\title{
Comparison Between Bivariate and Trivariate Flood Frequency Analysis Using the Archimedean Copula Functions, A Case Study of the Karun River in Iran
}

Mohamad Haytham Klaho

Isfahan University of Technology

Hamid R. Safavi ( $\nabla$ hasafavi@iut.ac.ir)

Isfahan University of Technology https://orcid.org/0000-0002-9233-9209

Mohamad H. Golmohammadi

Isfahan University of Technology

Maamoun Alkntar

Isfahan University of Technology

\section{Research Article}

Keywords: Flood frequency, Copula functions, Archimedean, Hierarchical, Return period

Posted Date: May 28th, 2021

DOI: https://doi.org/10.21203/rs.3.rs-524239/v1

License: (c) (i) This work is licensed under a Creative Commons Attribution 4.0 International License.

Read Full License

Version of Record: A version of this preprint was published at Natural Hazards on February 12th, 2022. See the published version at https://doi.org/10.1007/s11069-022-05240-y. 
2 Using the Archimedean Copula Functions, A Case Study of the Karun River

\section{in Iran}

Mohamad Haytham Klaho, MSc. Graduated, Dept. of Civil Engineering, Isfahan University of Technology, 8415683111, Isfahan, Iran. E-mail: eng.h.klaho@cv.iut.ac.ir

Hamid R. Safavi (corresponding author), Prof., Dept. of Civil Engineering, Isfahan University of Technology, 8415683111, Isfahan, Iran. Tel: ++983133913826, E-mail: hasafavi@iut.ac.ir

Mohammad H. Golmohammadi, Assist. Prof., Dept. of Civil Engineering, Isfahan University of Technology, 8415683111, Isfahan, Iran. Tel: ++983133913853, E-mail: m.golmohammadi@iut.ac.ir

Maamoun Alkntar, PhD Student, Dept. of Civil Engineering, Isfahan University of Technology, 8415683111, Isfahan, Iran. E-mail: m.alkntar@cv.iut.ac.ir

\section{Abstract}

15 Historically, severe floods have caused great human and financial losses. Therefore, the flood

16 frequency analysis based on the flood multiple variables including flood peak, volume and

17 duration poses more motivation for hydrologists to study. In this paper, the bivariate and trivariate

18 flood frequency analysis and modeling using Archimedean copula functions is focused. For this

19 purpose, the annual flood data over a 55-year historical period recorded at the Dez Dam

20 hydrometric station were used. The results showed that based on goodness of fit criteria, the Frank

21 function built upon the couple of the flood peak-volume and the couple of the flood peak-duration 
22 as well as the Clayton function built upon the flood volume-duration were identified to be the best

23 copula families to be adopted. The trivariate analysis was conducted and the Clayton family was

24 chosen as the best copula function. Thereafter, the common and conditional cumulative probability

25 distribution functions were built and analyzed to determine the periodic "and", "or" and

26 "conditional" bivariate and trivariate flood return periods. The results suggest that the bivariate

27 conditional return period obtained for short-term periods is more reliable than the trivariate

28 conditional return period. Additionally, the trivariate conditional return period calculated for long-

29 term periods is more reliable than the bivariate conditional return period.

30 Keywords: Flood frequency, Copula functions, Archimedean, Hierarchical, Return period.

\section{Introduction}

33 Flood is one of the most important natural disasters annually causing many financial and human

34 losses in different parts of the world, thus, its analysis and forecasting are required to control its

35 possibly acute damages. In the literature, Civil and Ashkar (1980), Silverman (1986), Correia

36 (1987), Gringorten (1963), Sackl and Bergmann (1987), all provided flood peak analysis with

37 limited assessment of flood events. While the study of many hydrological events requires thorough

38 knowledge of flood event (flood peak, flood volume, flood duration and hydrograph shape, etc.),

39 only a handful of researchers have attempted to address this issue. To predict floods in a certain

40 area, it is necessary to understand the three important characteristics of flood namely flood peak,

41 flood volume and flood duration, to perform a joint analysis of the flood data occurring in the past

42 in the area. One of the traditional methods for multivariate flood frequency analysis is the use of

43 classical multivariate distribution functions, such as normal, log normal, Gamma, etc..; however 
44 the main problem hindering employing these methods is that these functions face limitations that

45 either reduce the accuracy of the analysis or make it essentially impossible to be conducted. One

46 of the most important limitations to use these functions is the need to specify the parameters of the

47 distribution functions of marginal variables and their uniformity. As a result, when encountering

48 the above limitations, a method for multivariate analysis should replace the classical methods. One

49 of the most appropriate methods available is the use of a special class of multivariate probability

50 functions called Copula Functions In recent years, scientists have used copula functions to analyze

51 flood frequencies. Copula functions were first introduced by Sklar (1959). Different copula

52 functions used in different sciences Joe (1997), Nelsen (2006). Yue et al. (1999) showed that a

53 model for direct use of Gamble's bivariate limit distribution is suitable for analyzing the joint

54 distribution of two random variables. The Application of modeling copula functions in hydrology

55 and environmental modeling was first triggered by De Michele and Salvadori (2003). Favre et al.

56 (2004) concluded that the copula function approach allows one to model dependent structures

57 independently of marginal distributions, while this modeling is impossible when using classical

58 standard distributions. The results show that the use of copula functions is more appropriate

59 because it allows one to consider a wide range of correlations possibly occurring in hydrology. De

60 Michele et al. (2005) used the Archimedean bivariate copula functions to simulate flood peak and

61 flood volume to be able of constructing the artificial flood hydrographs. Modeling joint

62 distributions using copula functions mitigates the intrinsic limitations in the flood frequency

63 analysis by selecting different marginal distributions of the flood characteristics. In general, the

64 copula functions can better fit the joint probability distribution of the certain data to occur to the

65 experimental data really occurring in the nature, as shown by Zhang and Singh (2007). Genest et

66 al. (2007) presented the steps required to construct a copula function model for hydrological 
67 purposes and examined the performance of copula function models for modeling the flood peak

68 dependent on the flood volume. Klein et al. (2010) used a method for multivariate probability

69 analysis of flood variables using copula functions to cope with the overestimation of hydrological

70 risk usually caused by performing the univariate probability analysis. Salvadori and De Michele

71 (2010) expressed that the multivariate value-based models are essential tools for evaluation of the

72 potentially dangerous accidents as the target of this research outline how exploiting recent

73 theoretical developments in the theory of copula can easily construct the new multivariate extreme

74 value distributions. Due to the many storms that occurred in Taiwan, (Shiau et al. 2010), concluded

75 that the single univariate analysis could not show a significant relationship between correlated

76 variables. Therefore, this study uses copula functions to construct a common distribution of depth

77 and precipitation duration for storm data. Using Copula to construct a multivariate distribution

78 means that the effects of marginal variables can be separated from dependent variables. They

79 derived the depth-duration-frequency (DDF) formula based on the use of copulas to show the

80 common distribution of depth and duration of precipitation. Placket was chosen to construct the

81 DDF curves. DDF allows rain depth to be estimated for a specific duration of rainfall and return

82 period. This DDF formula improves the understanding of complex hydrological processes and

83 increases the design safety standard of hydraulic structures. Based on their research, an interesting

84 feature of Copula models is that any distribution can be used to display a marginal distribution.

85 Copula functions have been used in various problems in water management and hydrology such

86 as drought and flood frequency analysis. In their study, concluded that between families of Copula,

87 Gumbel functions, there is more correlation for large values and less correlation for small values,

88 whereas the opposite is true for Clayton Copula. Copula Frank has a lot of connection in the middle

89 and little in the bottom. 
90 Volpi and Fiori (2012) stated that in hydrological design and flood management, joint distribution

91 of flood peak and flood volume, on the one hand and that of the flood volume and flood duration,

92 on the other hand, are of particular importance. Therefore, many studies have been conducted to

93 perform multivariate flood frequency analysis considering the relationship between flood variables

94 including flood peak, flood volume and flood duration with restrictive assumptions. In the study

95 of Nashwan et al. (2018), bivariate frequency analysis of the flood in different stations of Kelantan

96 river basin was performed using copula functions to assess the geographical distribution of flood

97 risk. The joint dependent structures of flood variables were modeled using the Gamble copula

98 function. The results showed that different variables are corresponding to different distributions.

99 Also, the correlation analysis between the variables showed a strong relationship between them.

100 The joint distribution functions of flood peak and volume, flood peak and duration, and flood

101 volume and duration showed that the joint return period was much longer than the univariate return

102 period. According to the research $\mathrm{Li}$ et al. (2020), copula functions are very useful in flood

103 frequency analysis and can be used for the make the measures necessary to achieve optimal water

104 resources planning and management. Archimedean bivariate functions may not be generalized to

105 the multivariate functions unless additional conditions are imposed on them to construct the

106 Archimedean multivariate types of functions. Accordingly, flood analysis in three variables is

107 more extensively used and the results are more accurate. As a result, the analysis of flood frequency

108 should be carried out upon three variables. The main goal of this study is to investigate the

109 application of the strong Archimedean copula functions in trivariate flood frequency analysis. The

110 relationship between flood variables and frequency analysis of two and three flood variables

111 including flood peak, flood volume and flood duration, were established. The marginal values of 
112 these variables and the best family of copula functions were selected to be used in estimating the 113 conditional cumulative distribution as well as the combined return periods.

\section{Study Area and Data}

116 Study area and geographical location

117 Dez Dam Lake is located in the geographical location N323800 E482746 in Khuzestan province

118 (Fig. 1). The lake is located in the northwest of Dezful, $23 \mathrm{~km}$ north-east of Andimashk and behind 119 the two mountains Shaydab and Tenguan, and is included in the six provinces of Isfahan, 120 Khuzestan, Lorestan, Markazi, Hamedan and Chaharmahal Bakhtiari. The basic information 121 required for the study area includes the daily inflow of the dam over the last 55 years (from 122 24/9/1963 to 28/8/2018) which is obtained from the hydrometric station located at the inlet of Dez 123 dam. 


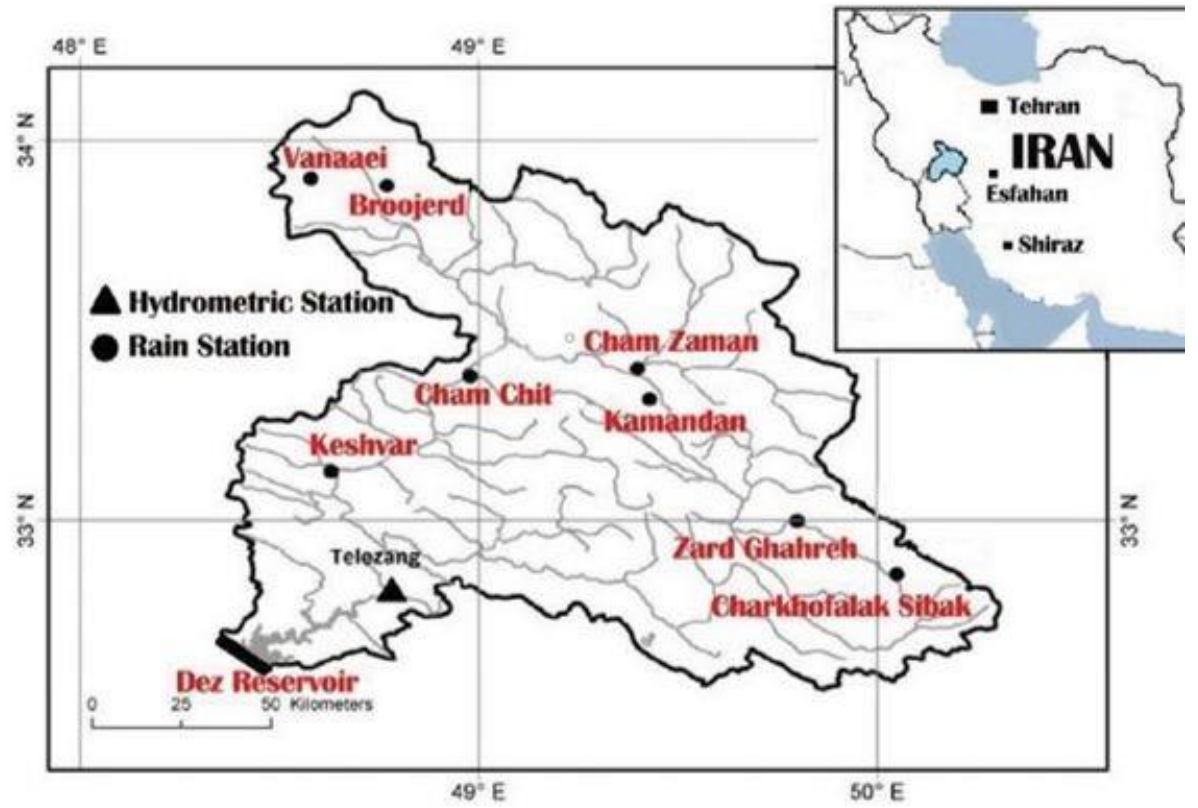

Fig.1 Location of Dez dam catchment and study area

129 The dam irrigates 125,000 hectares of downstream land and has played an important role in

130 controlling floods created upstream, especially in the last five years. The dam has a capacity of 131520 megawatts and a final capacity of 3.3 billion cubic meters of water (Felfelani, Movahed, \& 132 Zarghami, 2013).

\section{Materials and Methods}

\section{Archimedean Copula Functions}

135 Archimedean functions have very important characteristics and play an effective role in

136 hydrological works Salvadori and De Michele (2007).These functions are easily constructed and

137 have suitable properties making these functions be widely used in hydrological analysis Nelsen 
138 (2006). The main reasons why the Archimedean functions are so applicable in the field of 139 hydrological sciences may be listed as follows.

140 1- Simplicity of making the members of this class.

141 2- Many families of copula functions belong to this category.

1423 - This category has many desirable properties.

143 The multivariate Archimedean copula functions are defined as follows (Nelsen, 2006):

$144 C_{\theta(u, v)}=\Phi^{-1}[\Phi(u)+\Phi(v)]$

145 In this equation, $\boldsymbol{\theta}$ is a tunable parameter used to form $\boldsymbol{\Phi} ; \boldsymbol{\Phi}$ is the generating function having a 146 continuous, convex and strictly uniform shape; $u$ and $v$ are the functions of the marginal cumulative

147 distribution of the studied variables whose probability density function is uniform, expressed as $\mathrm{U}$ $148(0,1)$.

149 In this study, five functions of Clayton, Frank, Gamble, Ali Michael-Haq and Joe belonging to the 150 Archimedean family were used for bivariate and trivariate flood analyses. Table 1 describes the 151 Archimedean functions and the relevant relationships. In Table 1, $d$ is the number of variables, for 152 each of which a cumulative probability distribution function is already defined. 


\begin{tabular}{|l|c|c|c|}
\hline Name & Copula function & Generating function $\Phi(t)$ & Parameter $\theta$ \\
\hline Clayton & $\left(\sum_{i=1}^{d} u_{i}^{-\theta}-d+1\right)^{-1 / \theta}$ & $\frac{1}{\theta}\left(t^{-\theta}-1\right)$ & $(0, \infty)$ \\
\hline Ali-Mikhail-Haq & $\frac{\prod_{i=1}^{d} u i}{1-\theta \prod_{i=1}^{d}(1-u i)}$ & $\ln \left(\frac{1-\theta(1-t)}{t}\right)$ & $(-1,1)$ \\
\hline Gumbel-Hougaard & $\exp \left(-\left(\sum_{i=1}^{d}(-\ln u i)^{\theta}\right)\right.$ & $(-\ln t)^{\theta}$ & $(1, \infty)$ \\
\hline Frank & $-1 / \theta \ln \left(1+\frac{\prod_{i=1}^{d}\left(e^{-\theta u i}-1\right)}{\left(e^{-\theta}-1\right)^{d-1}}\right)$ & $-\ln \frac{e^{-\theta t}-1}{e^{-\theta}-1}$ & $(0, \infty)$ \\
\hline Joe & $1-\left[1-\prod_{i=1}^{d}\left(1-(1-u i)^{\theta}\right)\right]^{1 / \theta}$ & $-\ln \left[1-(1-t)^{\theta}\right]$ & $(1,+\infty)$ \\
\hline
\end{tabular}

159 Extract parameters (peak, volume, and duration of a flood event)

160 A portion of the river discharge is coming from the previous runoff, and to obtain the newly

161 generated flood hydrograph, firstly, it is necessary to subtract the previous river discharge, called

162 the base discharge, from the total existing runoff. This process is called the separation of the

163 hydrograph. The simplest way to separate the base flow hydrograph is drawing a line in the flood

164 hydrograph from the point where the flood begins (A) to the point where the flood ends (B). The 165 part of the hydrograph placed above the line $A B$ denotes the direct runoff hydrograph. Fig. 2 166 illustrates the duration of a flood occurrence by identifying the start and end time of the flood 167 runoff. The flood volume can be calculated using the Eq. (2) (Yue et al., 1999):

$V_{i}=\sum_{j=S D i}^{E D i} q_{i j}-\frac{1}{2}\left(q_{i s}-q_{i e}\right)$ 
169 where $q_{i j}$ is the $j$ th day observed daily streamflow value for the $i$ th year; $q_{i s}$ and $q_{i e}$ are observed 170 daily streamflow values on the start date and end date of flood runoff for the $i$ th year, respectively.

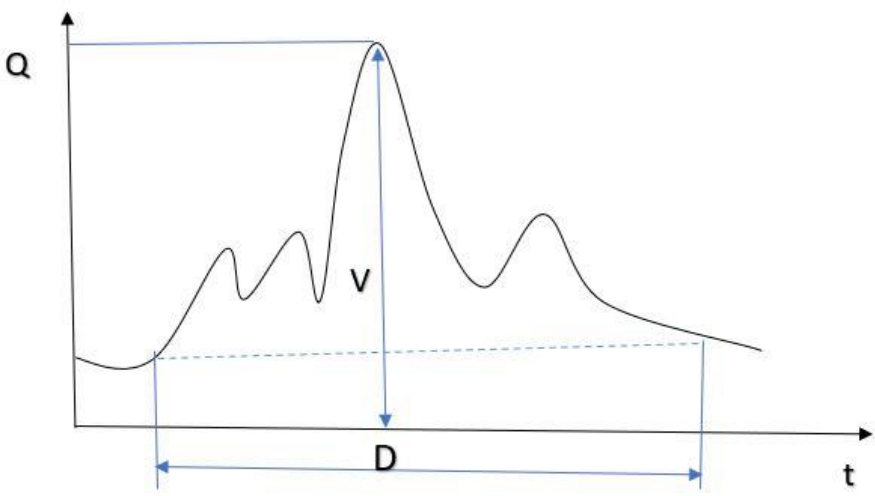

175 Correlation coefficients are the mathematical indicators showing the direction and value between 176 two variables as the observed and computed output of the multivariate distributions. To measure

177 the correlation, various coefficients are commonly used, including Pearson $(r)$, Kendall's tau $(\tau)$ 178 and Spearman $(\rho)$ correlation coefficients. In this study, all three mentioned correlation 179 coefficients have been used to examine the correlation between the variables and can be estimated 180 as follows (She \& Xia, 2018):

$181 \quad r=\frac{\sum_{i=1}^{n}(X i-\bar{X})(Y-\bar{Y})}{(n-1) \sqrt{S x^{2} S y^{2}}}$

$182 \tau=\frac{2}{n *(n-1)} \sum_{i=1}^{n-1} \sum_{j=i+1}^{n} \operatorname{sgn}((x i-x j)(y i-y j))$

$183 \rho=1-\frac{6 * \sum d^{2}}{n *\left(n^{2}-1\right)}$ 
184 Where $\bar{X}$ and $\bar{Y}$ are the mean of the data $(\mathrm{X}, \mathrm{Y}), S x^{2}$ and $S y^{2}$ are the variance of the data. $n$ is the 185 number of data and $\operatorname{sgn}(x)$ is the signal function. To calculate the Spearman coefficient, all $\mathrm{X}$ and 186 Y data are first ranked in terms of their values. Then, the difference between the elements of the 187 same pairs is denoted by $d$ and the number of the elements included in the two data sets is denoted 188 by $n$.

\section{Empirical Trivariate Probability}

190 The Gringorton experimental equation is one of the equations presenting the Empirical cumulative

191 distribution functions that is commonly used and derived from position mapping relations. The 192 probability of non-experimental encapsulation of the cumulative probability of Gringorton for the 193 three variables is obtained using the Eq. (6) (Zhang \& Singh, 2006):

$194 P(X \leq x, Y \leq y, Z \leq z)=\frac{\sum_{m=1}^{i} \sum_{l=1}^{i} \sum_{c=1}^{i} n_{m}-0.44}{N+0.12}$

195 where $n_{m}$ is the number of three variables $(X i, Y i, Z i)$ provided that $X j<X i, Y j<Y i$ and $Z j<Z i$ 196 and $\mathrm{N}$ is sample size.

\section{Estimation of the Copula Parameters}

199 Estimation of the parameters of the copula functions can be done utilizing various methods. To 200 select the best copula function, the best form of correlation relation between the parameters must

201 be obtained. The steps governing the selection of a copula function are generally presented by 202 either of these two methods: (1) Kendall correlation method, and (2) Likelihood method. In this 203 research, the Likelihood method has been used to estimate the model parameters. The basis of this 204 method is to look for the best value of a probability distribution parameter, which should be the 
205 value maximizing the likelihood or probability of the observed sample to occur. For simplicity,

206 the logarithm of the likelihood function is used instead of the likelihood itself. This summation of

207 the natural logarithms illustrated in Eq. (7) should be maximized to cause the multiplication of the

208 likelihoods to go to the value 1 as the maximum correlation there may be between the marginal

209 cumulative probability distribution function values.

$210 \quad \operatorname{Lnl}=\sum_{i=1}^{n} \operatorname{Ln}[C(u, v) i]$

211 where the maximum value of $\operatorname{Lnl}$ appears when at $(\partial(\operatorname{Lnl}) / \partial \theta=0$.

212

213 Goodness of Fit

214 The purpose of evaluating the goodness of fit of a couple of data sets is to select the most

215 appropriate and best copula function that shows the structure of the dependence between the 216 variables and the behavior of the copula functions well. There are graphical tools and numerical

217 tests to achieve this goal, including Akaike, Root-Mean-Square Error, Nash-Sutcliffe, Max

218 Likelihood and Q_Q plot graph. The mentioned indicators are obtained from the Eqs. (8-11):

$219 A I C=N \log (M S E)+2(P)$

$220 \quad R M S E=\sqrt{\frac{1}{n}} \sum_{i=1}^{n}(A i-P i)^{2}$

$221 \quad N S E=1-\frac{\sum_{i=1}^{n}\left(Q_{m}^{i}-Q_{0}^{i}\right)^{2}}{\sum_{i=1}^{n}\left(Q_{0}^{i}-\overline{Q_{0}}\right)^{2}}$

$222 l(\theta)=\sum_{i=1}^{n} \log \left[c_{\theta}(F(X i), \quad F(Y i))\right]$ 
223 where $\mathrm{N}$ is the number of observations; MSE is the mean squared error and $\mathrm{P}$ is the number of

224 fitted parameters; $A i$ represents observed values; $P i$ represents the computed values; $Q_{m}^{i}$ represents

225 the computed values; $Q_{0}^{i}$ expresses the observed values; and $\overline{Q_{0}}$ expresses the average of the

226 observed values. It is worth mentioning that the lower the values of the AIC and RMSE, the better

227 the copula functions are fitted to the data and the higher the values of the NASH and Likelihood,

228 the better the copula functions are fitted to the data.

Joint and Conditional Cumulative Probability Distribution Functions and return period

231 After selecting the best copula function for the two- and three-variable modes, the two- and three-

232 variable conditional cumulative distribution functions and return periods for the different modes

233 are obtained. Joint probability distribution is the probability of both the peak flow of the flood and

234 the volume of the flood would be above a certain threshold. Analysis of flood parameters is an

235 important factor in the management of this phenomenon, helping the managers and planners

236 achieve a better understanding of this phenomenon and improve their decision-making process

237 and planning thanks to this understanding. Also, the conditional cumulative distribution function

238 of the three variables $X \leq x$ and $Y \leq y$ for different values of $Z=z$ can be written as follows.

$239 \quad F(x, y \mid \mathrm{Z} \leq \mathrm{z})=\frac{F_{x, y, z}(x, y, z)}{F_{z}(z)}$

240 In general, the calculation and estimation of the return period is based on the statistical

241 measurement of the historical data and is beneficial to obtain the average repetition time of a

242 phenomenon in a time period and is used to analyze the risk of a phenomenon such as a flood

243 event. The return period of an event upon emergence of either of the three conditions, which here 
244 we express it as "or" relation between these conditions, is the return period of the intersection $T_{x, y, z}^{\cup}$

245 of the three variables representing the events where $(X \geq x$ or $Y \geq y$ or $Z \geq z)$ and is defined as 246 follows.

$247 \quad T_{x, y, z}^{\cup}=T_{X, y, z}^{o r}=\frac{1}{F^{\prime(X \geq x \cup Y \geq y \cup Z \geq z)}}=\frac{1}{1-C(x, y, z)}$

249 Results and Discussion

250 Determining the Correlation Coefficients of the Parameters

251 The correlation coefficients between the variables were calculated and according to the results

252 shown in Table 2, there is a significant and direct correlation between the flood peak and volume

253 and between the flood volume and duration while there is an inverse correlation between flood

254 peak and duration. Furthermore, the correlation between the flood volume and duration is stronger

255 than the correlation between the flood peak and volume as well as the correlation between flood

256 peak and duration.

Table 2 Values of correlation coefficients between parameters

\begin{tabular}{|c|c|c|c|}
\hline Correlation coefficients & Flood peak and volume & Flood peak and duration & Volume and duration \\
\hline Kendall's tau $(\tau)$ & 0.204 & -0.2459 & 0.5106 \\
\hline Spearman $(\rho)$ & 0.3047 & -0.3476 & 0.688 \\
\hline Pearson $(r)$ & 0.2749 & -0.3177 & 0.6575 \\
\hline
\end{tabular}


261 The selection of marginal distribution functions is done based on Anderson Darling test and

262 Kolmogorov-Smirnov test. The flood peak, volume and duration data were fitted and the results

263 showed that the best probability distribution function on the flood peak data is the log normal

264 distribution function. The gamma distribution function was generalized to the volume data and the

265 Generalized Extreme Value function was generalized to the duration data. Based on this, the

266 parameters of log normal, gamma and Generalized Extreme Value distribution functions are given

267 in Table 3.

Table 3 Parameters of selected probability distribution functions

\begin{tabular}{|c|c|c|c|c|c|c|}
\hline \multirow{2}{*}{ Variable } & Selected distribution & \multicolumn{4}{|c|}{ Parameters of selected probability distribution functions } \\
\cline { 3 - 7 } & function & $\boldsymbol{\mu}$ & $\boldsymbol{\sigma}$ & $\boldsymbol{\alpha}$ & $\boldsymbol{\beta}$ & $\mathbf{k}$ \\
\cline { 3 - 7 } & Leak flood & 7.478 .2 & 0.576188 & ---- & ---- & ---- \\
\hline Volume & Gamma & ---- & ---- & 2.00274 & 12843 & ---- \\
\hline Duration & Generalized Extreme Value & 63.6923 & 35.449 & ---- & ---- & 0.0107922 \\
\hline
\end{tabular}

\section{Estimation Parameters and Goodness of Fit}

271 Since the main purpose of this research is to model two and three flood variables, the parameters

272 of five family of copula functions including (Clayton, Frank, Gamble, Ali Mikhail -Haq and Joe)

273 were calculated. How to estimate the parameters of these functions are fully described in Section

274 3.5. The values estimated for the parameters for the bivariate model through the Maximum

275 Likelihood Method with an approximate 95\% confidence interval can be seen in Tables 4, 5 and

276 6. Also, the Q_Q graphs are shown in Fig. 3 (a, b, and c). Also, the assumed range of the parameter 
$277 \boldsymbol{\theta}$ is given in these tables. Since the parameter $\boldsymbol{\theta}$ of the Joe function coupling the probability of the

278 flood peak and flood duration was outside of previously adopted range of the parameter, the

279 modeling of the Joe function for this condition was avoided. The final selection of the copula

280 function was done upon evaluating the performance of every copula function generated with

281 respect to the measures described in section 3.6. As implicitly mentioned before, the lower the

282 AIC and RMSE; the higher the estimation accuracy; and the higher the NSE criterion; the more

283 accurate the model. Regarding the Maximum Likelihood criterion, the higher the value of this

284 measure, the more acceptable it is. Having compared the performance of the different copula

285 functions when applied to fitting a certain couple of the marginal distributions, the best bivariate

286 copula between flood peak and volume and between flood peak and duration was revealed to be

287 the Frank family, while the Clayton family was identified as the best bivariate copula between the 288 flood volume and duration. 


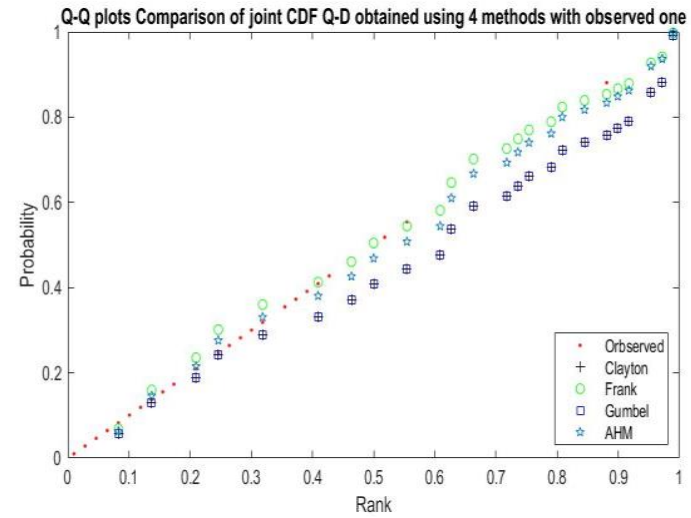

(a)

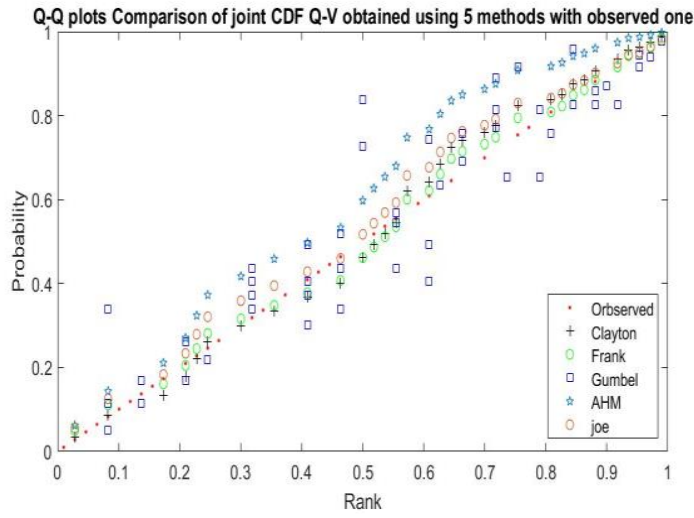

(b)

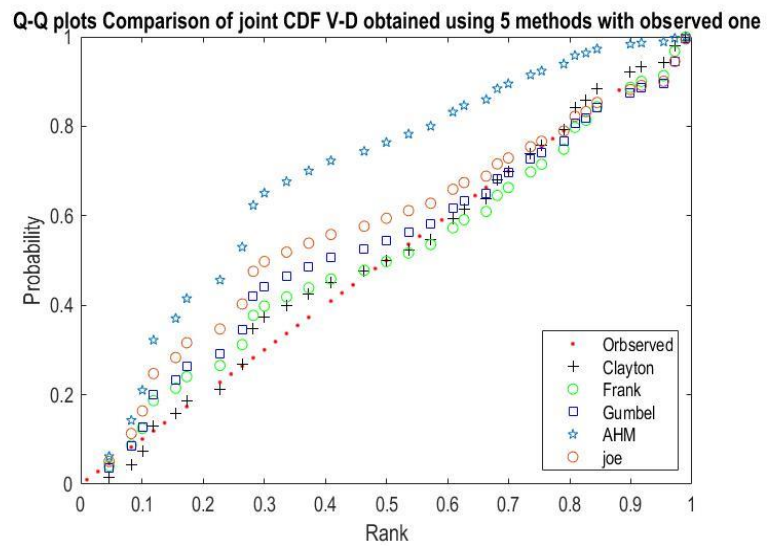

(c)

294 Fig. 3 Curve Q-Q plot. (a) between flood peak and flood volume. (b) between flood peak and flood duration. (c) 
Table 4 Goodness of fit test results of fitting the bivariate copula functions between flood peak and volume

\begin{tabular}{|l|c|c|c|c|c|}
\hline Copula function & parameter & Max log likelihood & AIC & RMSE & NSE \\
\hline Clayton & 0.35 & 200.02 & -40 & 0.195 & 0.988 \\
\hline Frank & $\mathbf{1 . 7 2}$ & $\mathbf{2 0 8 . 2}$ & $\mathbf{- 4 1 . 6 4}$ & $\mathbf{0 . 1 6 8}$ & $\mathbf{0 . 9 9 1}$ \\
\hline Gamble & 1.15 & 200.84 & -40.17 & 0.192 & 0.989 \\
\hline Ali Mikhail Haq & -0.77 & 76.8 & -15.36 & 1.835 & -0.021 \\
\hline Joe & 1.15 & 191.17 & -38.23 & 0.229 & 0.984 \\
\hline
\end{tabular}

303

304 Table 5 Goodness of fit test results of fitting the two-variable copula functions between flood peak and duration

\begin{tabular}{|l|c|c|c|c|c|}
\hline Copula function & parameter & Max log likelihood & AIC & RMSE & NSE \\
\hline Clayton & 0 & 165.89 & -33.18 & 0.363 & 0.92 \\
\hline Frank & $\mathbf{- 2 . 1 4}$ & $\mathbf{1 8 2 . 3 7}$ & $\mathbf{- 3 6 . 4 7}$ & $\mathbf{0 . 2 6 9}$ & $\mathbf{0 . 9 5 6}$ \\
\hline Gamble & 1 & 165.89 & -33.18 & 0.363 & 0.92 \\
\hline Ali Mikhail Haq & -0.96 & 67.65 & -13.53 & 2.168 & -1.875 \\
\hline Joe & ----- & ---- & ---- & ---- & --- \\
\hline
\end{tabular}

306 Table 6. Goodness of fit test results of fitting the two-variable copula functions between flood volume and duration

\begin{tabular}{|l|c|c|c|c|c|}
\hline Copula function & parameter & Max log likelihood & AIC & RMSE & NSE \\
\hline Clayton & $\mathbf{1 . 7 6}$ & $\mathbf{1 8 4 . 6 3}$ & $\mathbf{- 3 6 . 9 3}$ & $\mathbf{0 . 2 5 8}$ & $\mathbf{0 . 9 8 1}$ \\
\hline Frank & 5.58 & 179.15 & -35.83 & 0.285 & 0.976 \\
\hline Gamble & 1.76 & 170.67 & -34.13 & 0.333 & 0.968 \\
\hline Ali Mikhail Haq & -0.71 & 74.52 & -14.9 & 1.913 & -0.061 \\
\hline Joe & 1.84 & 157.15 & -31.43 & 0.278 & 0.947 \\
\hline
\end{tabular}

307 
308 In addition to modeling the bivariate copulas, the purpose of this study is also to determine the

309 best trivariate copula function with respect to the Maximum Likelihood values calculated for each

310 of the copulas shown in Table 7. It is worth mentioning that which data (flood peak or volume or

311 duration) is sorted in an ascending order, the results of the copula parameter are the same. Because

312 the Gamble copula function parameter is not in the range of its variations, it cannot be modeled in

313 the trivariate form. According to the goodness-of-fit results presented in Table 7 and the

314 corresponding plots depicted in Fig 4, the Clayton function is the best trivariate function for fitting

315 the joint probability to all the flood variables involved in this study.

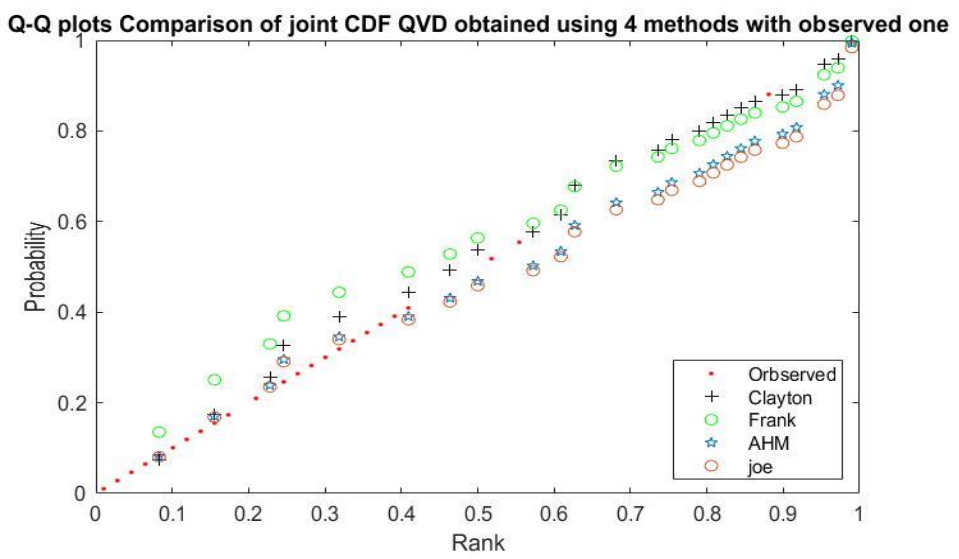

Fig.4 Curve Q_Q plot for three variables 


\begin{tabular}{|l|c|c|c|c|c|}
\hline Copula function & parameter & Max log likelihood & AIC & RMSE & NSE \\
\hline Clayton & $\mathbf{0 . 3 1}$ & $\mathbf{1 6 5 . 5 8}$ & $\mathbf{- 3 3 . 1 2}$ & $\mathbf{0 . 3 6 5}$ & $\mathbf{0 . 9 1 6}$ \\
\hline Frank & 1.27 & 163.19 & -32.64 & 0.382 & 0.908 \\
\hline Gamble & ---- & ---- & ---- & ---- & ---- \\
\hline Ali Mikhail Haq & 0.08 & 150.59 & -30.12 & 0.48 & 0.855 \\
\hline Joe & 1.13 & 155.57 & -31.11 & 0.438 & 0.879 \\
\hline
\end{tabular}

329 Some important information for flood management can be obtained from the joint probability

330 distribution resulting from copula functions. The probability of both the flood peak and the flood

331 volume to be above a certain threshold is an important condition triggering a flood warning system

332 and would be the start point for emergency flood planning. After selecting the best copula function

333 with reference to the goodness of fit criteria, the joint probability distribution curves/surfaces of

334 the pairwise variables involved in the flood were plotted. In detail, joint probability distribution in

335 addition to contour lines of the joint probability distribution, between flood peak and volume,

336 between flood peak and duration, and between volume and duration of flood as well as joint

337 probability of three variables for the fixed 60-day flood duration, are shown in Figs. 5, 6, 7, and 8. 

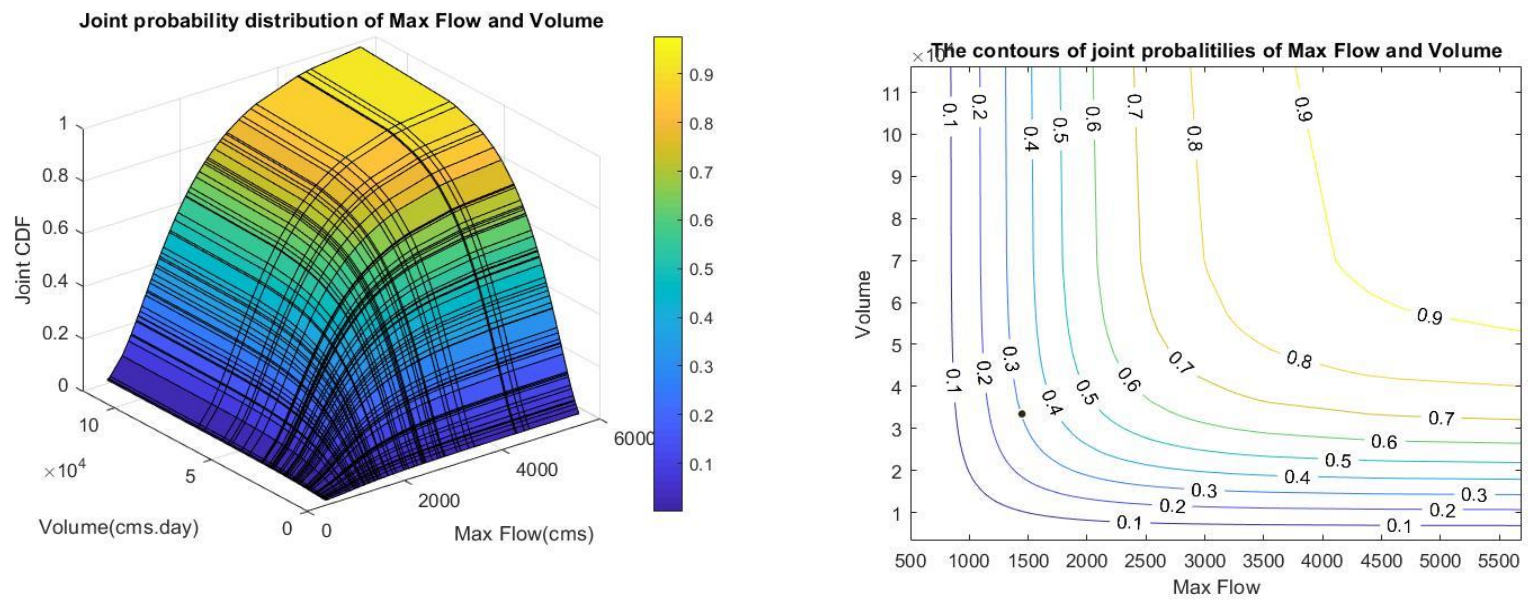

Fig.5 Joint Probability and contour lines of Frank distribution between flood peak and flood volume
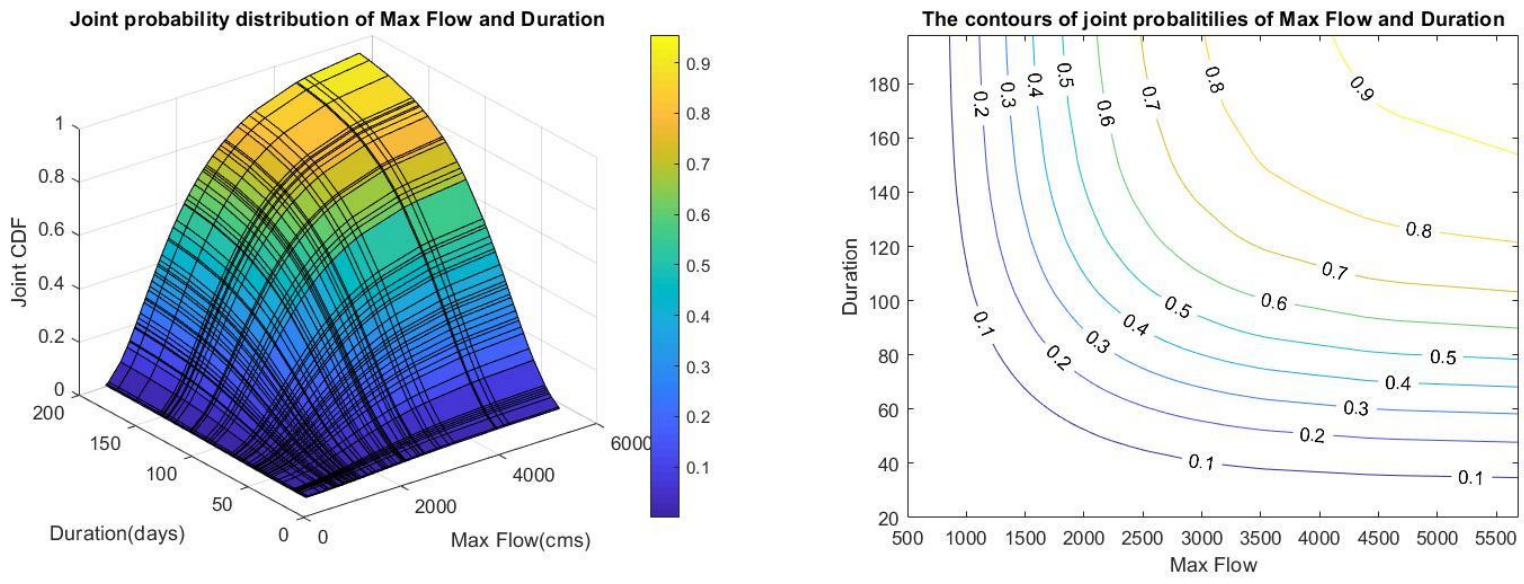

Fig.6 Joint Probability and contour lines of Frank distribution between flood peak and flood duration 

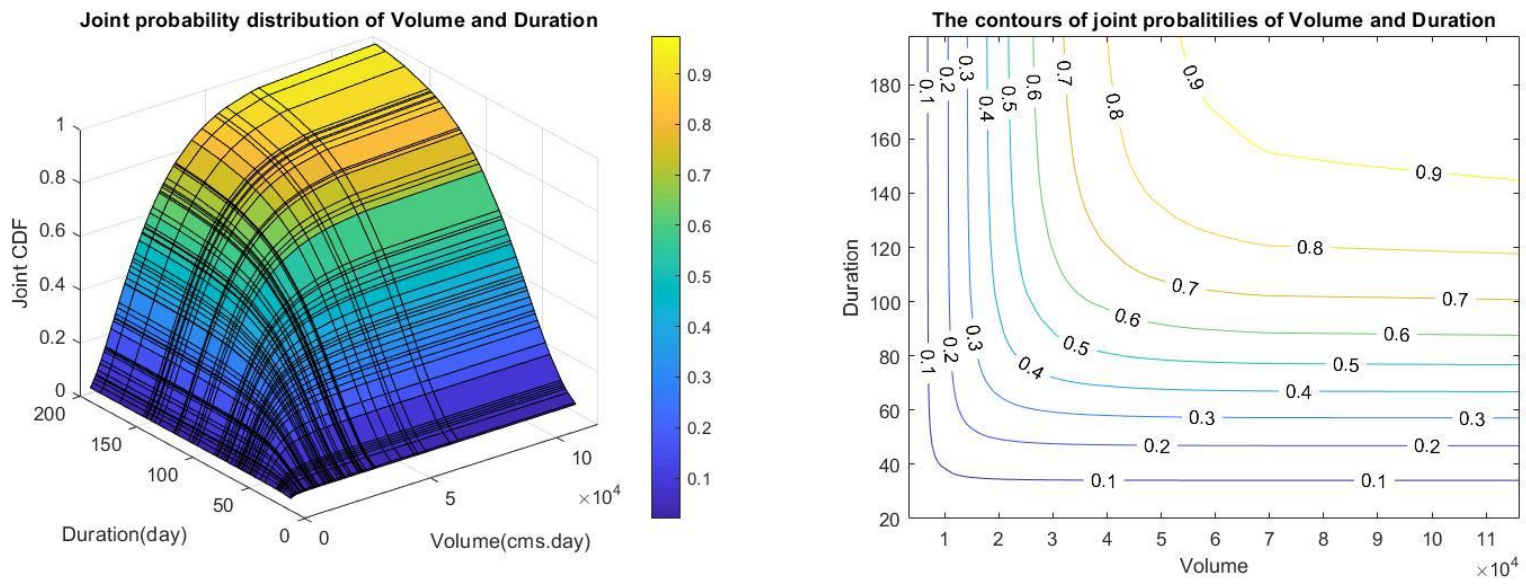

Fig.7 Joint Probability and contour lines of Clayton distribution between flood volume and flood duration
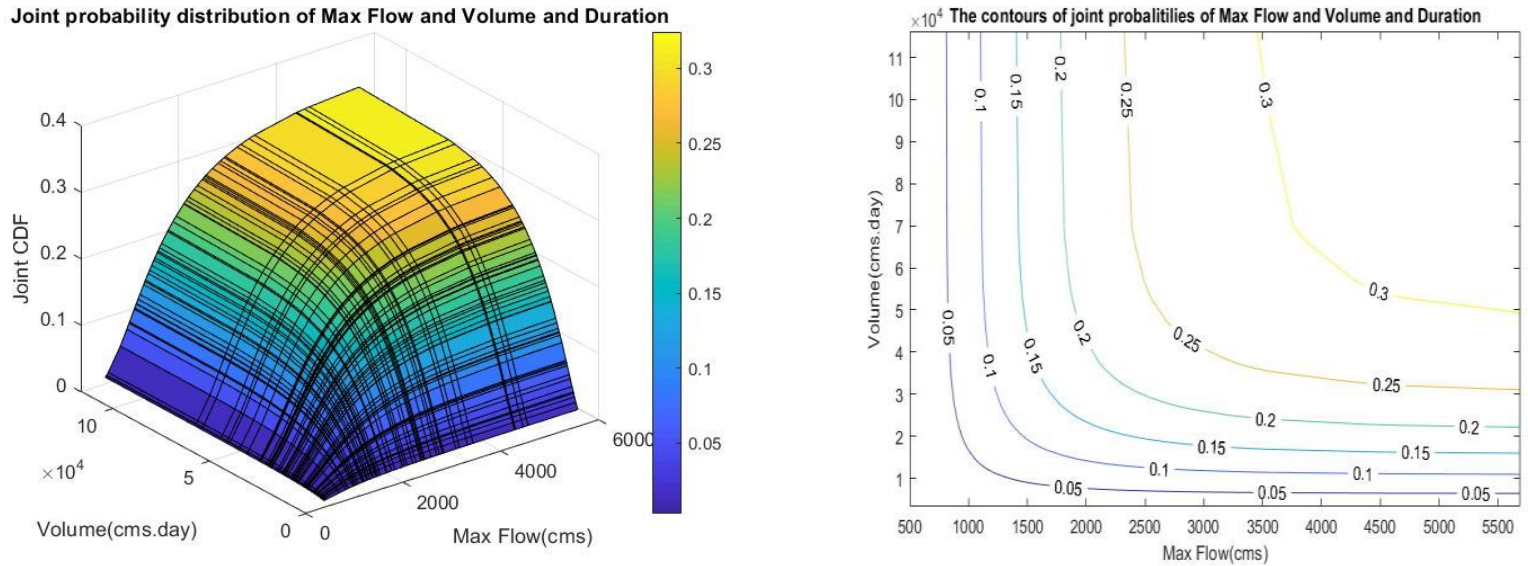

Fig.8 Joint Probability and contour lines of Clayton distribution between flood peak, volume, and duration

339 In multivariate flood frequency analysis, flood variables are sometimes assumed to be independent

340 variables without considering the variance/covariance structure of flood variables. Using the

341 copula function of the selected two variables, the return period of type "or" corresponding to both 
342 series of flood parameters as well as the contour lines can be calculated and plotted, as shown in

343 Figs. 9, 10, and 11. Comparing the return periods of the pairwise variables for different cases

344 illustrated in Figs. 9, 10, and 11, the maximum return period is obtained to be 44 years based on

345 the copula function built upon the case of the flood peak,-flood volume. This return period is taken

346 into account as the highest and thus, the most critical return period of the flood events in a historical

347 period and can be used to predict the flood risks at the future. In order to detect the difference in

348 the return period obtained based on different hypotheses, the conditional return periods were

349 calculated upon the bivariate and trivariate copula functions and compared. As an example, the

350 standard conditional return periods of the flood peak limited by a certain volume and a certain

351 duration of the flood, are depicted in Table 8. The results show that the flood peak extracted from

352 a bivariate copula is greater than that extracted from a trivariate copula for the return periods less

353 than or equal to 20 years. Thus, the bivariate conditional return period s for a short-term period is

354 more reliable than the trivariate conditional return period. While, for the return periods longer than

35520 years and up to 100 years, the flood peak derived from a trivariate copula is greater than that

356 derived from a bivariate copula, meaning that the trivariate conditional return period for a long-

357 term period is more reliable than the bivariate conditional return period. Also, the flood peak

358 extracted from the Standard "or" bivariate and trivariate conditional return periods when the

359 volume and duration of the flood are limited are shown in detail in Table 9. Note that in this table,

360 the return period is "or", after one year. The flood peak derived from the trivariate conditional

361 copula of type "or" is greater than that derived from the bivariate conditional copula of type "or",

362 meaning that if decided to achieve more reliable flood peaks and thus, to make the more reasonable

363 decisions, the conditional return periods should be calculated based on the conditional copulas of

364 type "or". In addition, the conditional return periods calculated by the trivariate Clayton function 
365 for a fixed 60-day flood duration versus the flood peak and volume are shown in both forms of the

366 surface and contours in Fig. 12.

Table.8. The return period of the two and three-variable conditional standard and its peak discharge

\begin{tabular}{|c|c|c|c|}
\hline & Peak flood Q (CMS) & Peak flood Q (CMS) & Peak flood Q (CMS) \\
\hline $\begin{array}{c}\text { Conditional return } \\
\text { period }\end{array}$ & $\begin{array}{c}(V=v, D=d) \\
(v=80000 \text { CMS*day, } \\
d=60 \text { day })\end{array}$ & $d=60 d a y$ & $\mathrm{v}=80000 \mathrm{CMS} *$ day \\
\hline 1.01 & 385.877 & 461.94 & 460.8 \\
\hline 2 & 1514.2 & 1768.7 & 1764.8 \\
\hline 5 & 2564.6 & 2872.5 & 2867.4 \\
\hline 10 & 3404.4 & 3701.3 & 3695.6 \\
\hline 20 & 4350.9 & 4563.1 & 4556.9 \\
\hline 50 & 6007.5 & 5775.4 & 5768.6 \\
\hline 100 & $8794 . .4$ & 6757.7 & 6750.4 \\
\hline
\end{tabular}

Table.9. The return period of the two and three-variable "or" standard and its peak discharge

\begin{tabular}{|c|c|c|c|}
\hline & Peak flood Q (CMS) & Peak flood Q (CMS) & Peak flood Q (CMS) \\
\hline $\begin{array}{c}\text { “or” return } \\
\text { period }\end{array}$ & $\begin{array}{c}(V=v, D=d) \\
(v=80000 \text { CMS } * \text { day, } \\
\text { d=60day })\end{array}$ & d=60day & $\mathrm{v}=80000 \mathrm{CMS} *$ day \\
\hline 1.01 & 462.88 & 462.23 & 464.4 \\
\hline 2 & 1810.2 & 1783.4 & 1800.6 \\
\hline 5 & 3063.4 & 2938.1 & 2995.6 \\
\hline 10 & 4227.5 & 3866.4 & 4009.1 \\
\hline 20 & 6416.4 & 4973.4 & 5391.2 \\
\hline
\end{tabular}



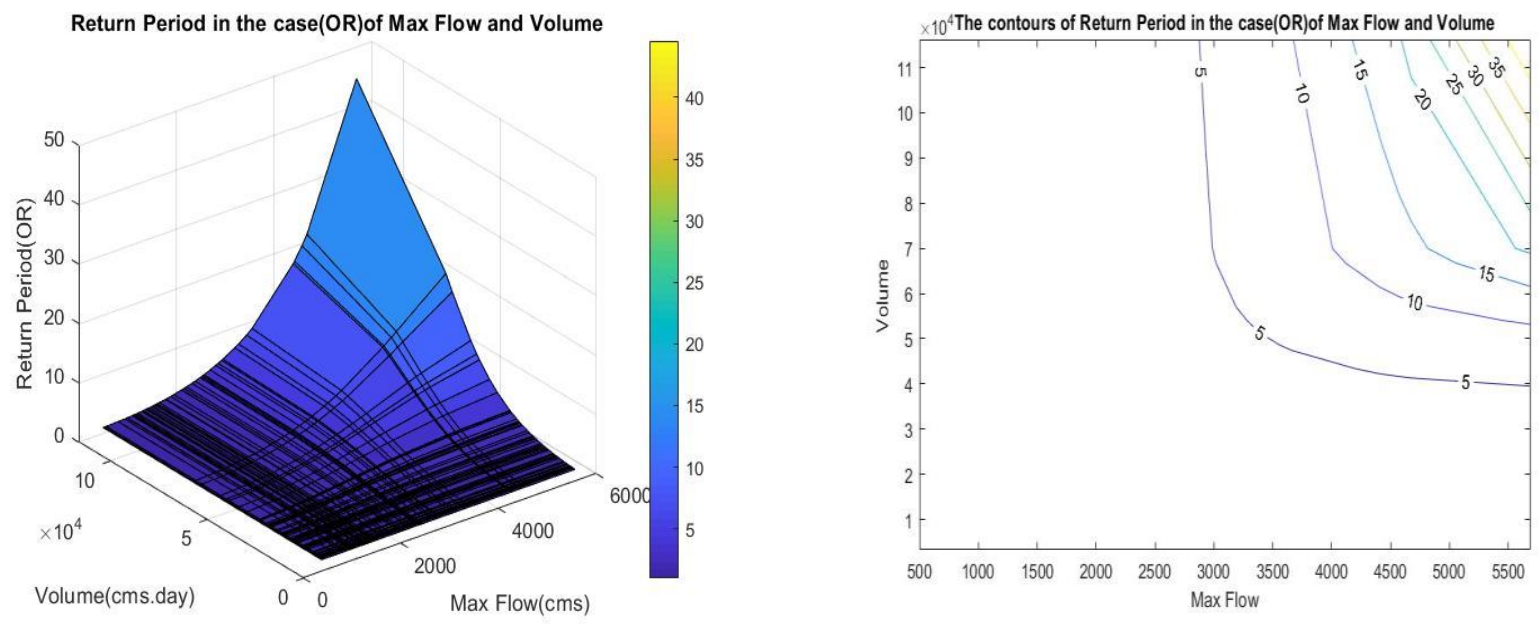

Fig.9 Return period and contour lines of the return period obtained by bivariate Frank function of type "or" between peak flow and flood volume
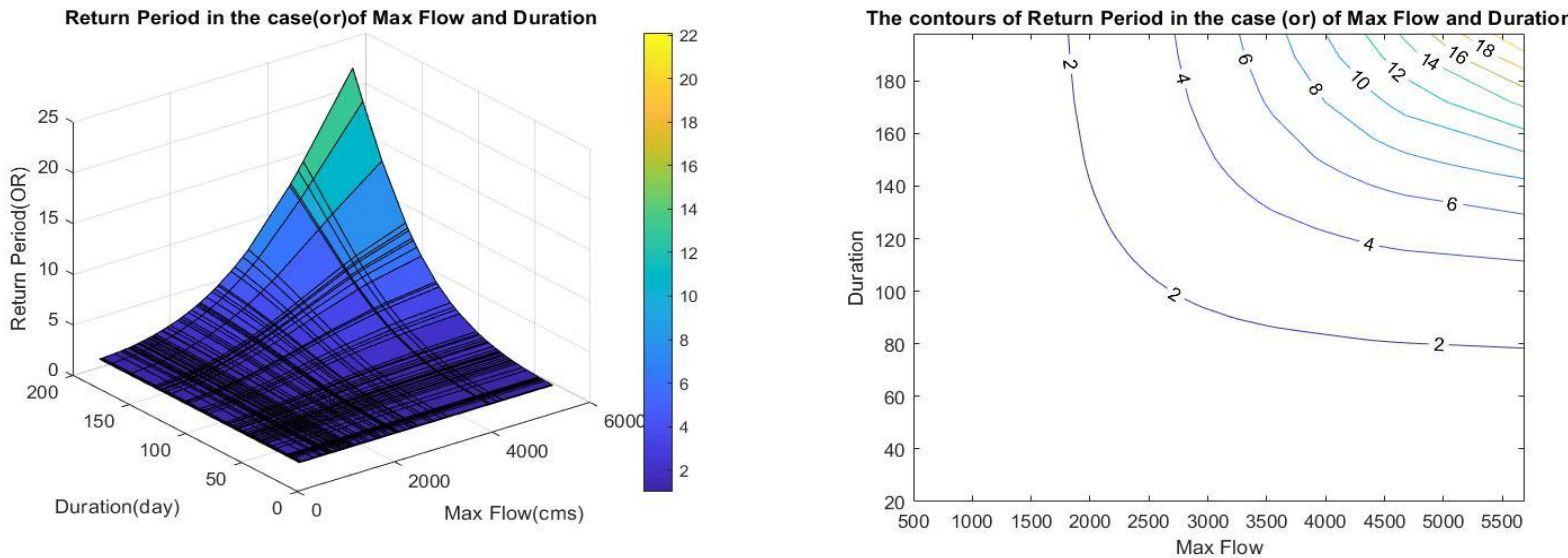

Fig.10 Return period and contour lines of the return period obtained by bivariate Frank function of type "or" between peak flow and duration 

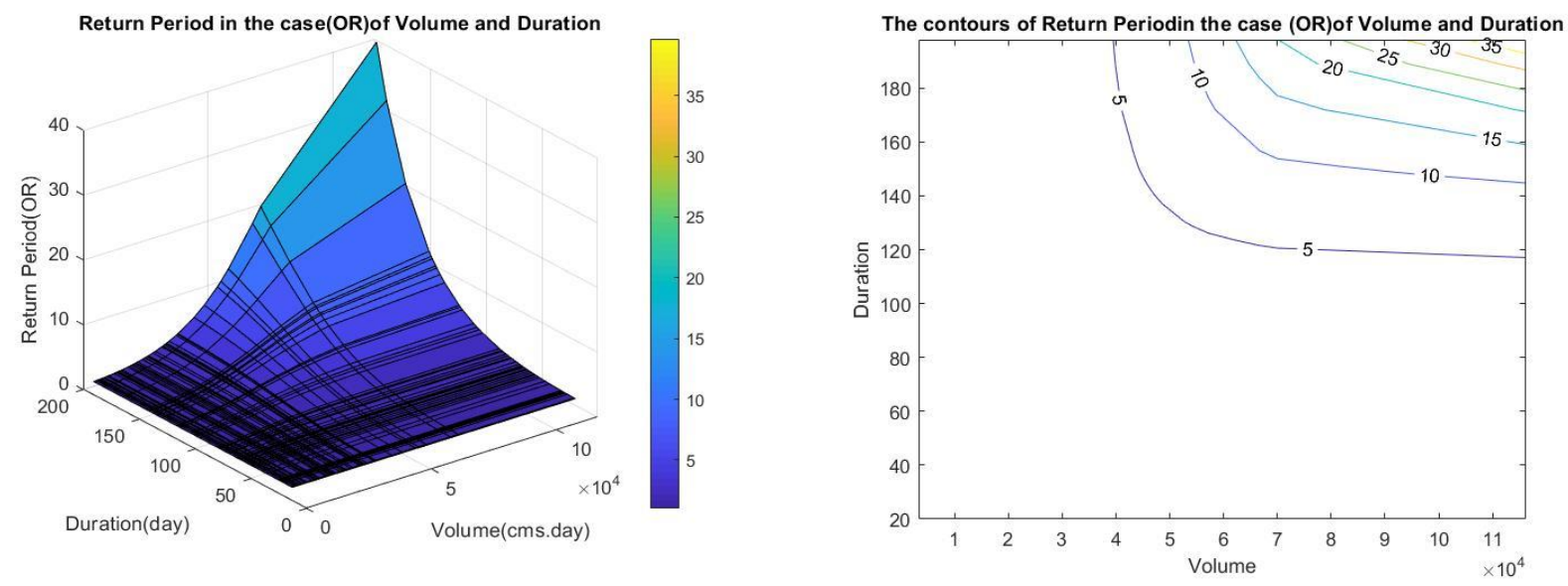

Fig.11 Return period and contour lines of the return period obtained by bivariate Clayton function of type "or" between volume and duration
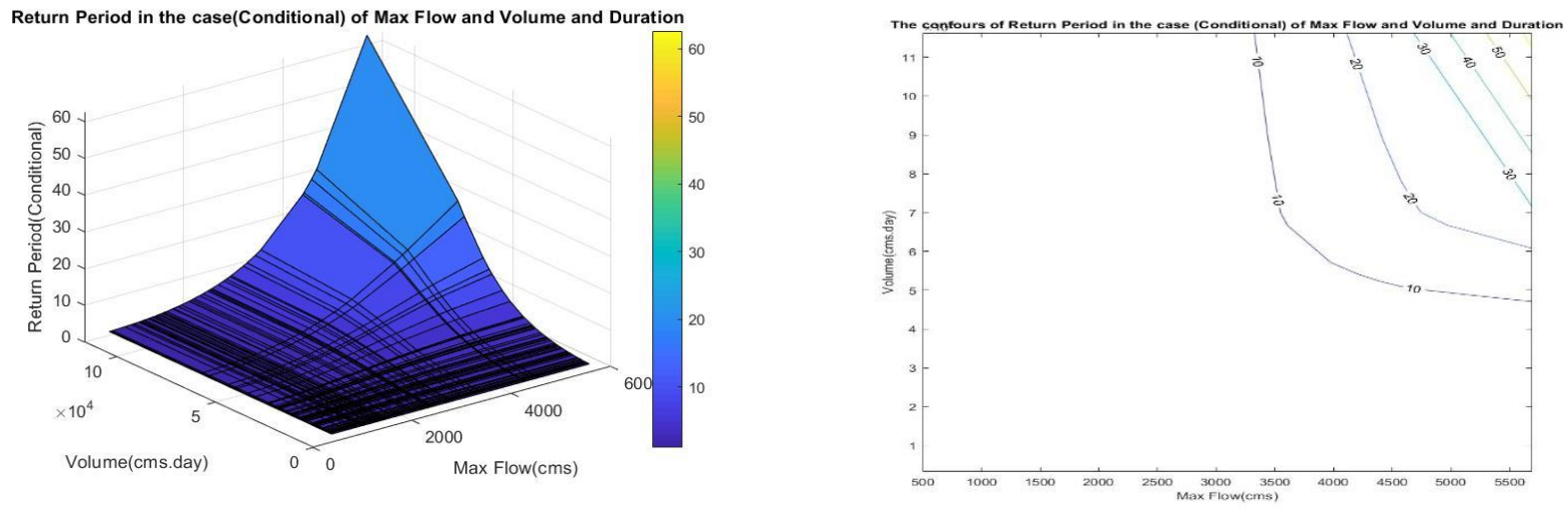

Fig.12 Conditional return period of three variables and contour lines for the 60-day flood duration

\section{Conclusion}

371 In recent decades, the phenomenon of flood has caused a lot of human and financial losses and

372 irreparable damages. Knowing the flood encompasses several characteristics considered as its

373 influential variables such as flood peak, flood volume and flood duration, the univariate analysis 
374 of flood frequency may make some errors. Therefore, trivariate flood frequency analysis should

375 be considered as a method to thoroughly characterize the flood events and the probability of them

376 to occur in the future. It is worth mentioning that the abovementioned flood variables (peak,

377 volume, and duration) are random in nature and are correlated in pairs. The copula functions as

378 the alternative functions could significantly raise the accuracy in the flood frequency predictions

379 as a result of lacking all the limitations of the classical functions. Among the copula functions, the

380 Archimedean functions are of three major advantages:(1) the ability to make multivariate analysis;

381 (2) the ability to involve the correlation between the multiple studied variables in the analysis; and

382 (3) the ability to define the marginal distributions of different families for different multiple

383 variables. With respect to these benefits of using the Archimedean copulas functions were used to

384 analyze the flood frequency and determine the return periods in different cases of the variables

385 combinations. Each variable can be better fitted and estimated by a specific probability distribution

386 function. These functions are experimentally determined to be the log normal, gamma, and

387 Generalized Extreme Value functions for the flood peak, flood volume and flood duration,

388 respectively. Thereafter, the parameters of the distribution functions were estimated and tuned

389 using the maximum likelihood method. The Frank copula family was adopted for modeling and

390 coupling the probability functions fitted to the three pairs of the flood variables including the peak-

391 volume, the peak-duration, also the volume-duration Moreover, the Clayton family was selected

392 for the volume- duration couple. Due to the importance of considering the trivariate form for any

393 flood frequency analysis, in this study, this type of the analysis was also conducted. We concluded

394 that the best trivariate copula function for the flood frequency analysis in the case study of this

395 study is the Clayton family. Estimating the joint probability of the flood occurrence affected by

396 two and/or three variables was calculated and plotted to be used for providing the future 
management plans related to water resources, risk analysis, contingency planning and flood

398 warning. Return period is the average time that an event, such as flood, is expected to occur at the

399 maximum magnitude. To better understand the concept of return period, the return period of two

400 and three variables of the type "or" and "Conditional" was defined and discussed. The results of

401 comparing the return period of the type "or" for two variables for different cases of the variable

402 combination of showed that the return period "or" for the bivariate flood peak-flood volume) is

403 less than the other cases, making the flood occurrence more reliable with these return periods.

404 Therefore, the return period is proposed to be estimated for this combination (flood peak-flood

405 volume), whenever decided to conduct the bivariate analysis. Furthermore, the results of

406 conducting the trivariate analysis suggested that the estimated risk of the flood occurrence

407 considering three variables is higher than that considering resulting from the univariate or bivariate

408 analysis in the long-term, as Nashwan et al. (2018) concluded in their research. We conclude that

409 the return period calculations for the bivariate cases and in the short-term period are more reliable

410 than those in the case of the trivariate analysis, but the trivariate conditional return period

411 calculated for the long-term periods is more reliable to come true than that calculated in the case

412 of bivariate analysis. In addition, the flood peak occurring in the same return periods calculated by

413 the copulas of type "or" is greater than that while occurring in the "conditional" return periods.

414 Thus, the return periods of the type "or" is of higher risk of occurrence as they are lower than the

415 other return periods calculated by another methods and thus, may be more reliable to be used for

416 flood management purposes in the future. As the overall results suggest, it is recommended to

417 perform similar flood frequency analysis in other important basins of the Karun River. These

418 analyses can be useful for risk assessment related to hydrological issues including overflow design

419 and flood management to take more reasonable and reliable control measures. 


\section{Conflict of Interest:}

421 There is no conflict of interest.

\section{References}

424 Civil, É. p. D. d. g., \& Ashkar, F. 1980. Partial duration series models for flood analysis: École $425 \quad$ polytechnique de Montréal.

426 Correia, F. N. 1987. Multivariate partial duration series in flood risk analysis, Hydrologic Frequency Modeling: 541-554: Springer.

De Michele, C., \& Salvadori, G. 2003. A generalized Pareto intensity-duration model of storm rainfall exploiting 2-copulas. Journal of Geophysical Research: Atmospheres, 108(D2).

De Michele, C., Salvadori, G., Canossi, M., Petaccia, A., \& Rosso, R. 2005. Bivariate statistical

Favre, A. C., El Adlouni, S., Perreault, L., Thiémonge, N., \& Bobée, B. 2004. Multivariate approach to check adequacy of dam spillway. Journal of Hydrologic Engineering, 10(1): hydrological frequency analysis using copulas. Water Resources Research, 40(1).

Felfelani, F., Movahed, A. J., \& Zarghami, M. 2013. Simulating hedging rules for effective reservoir operation by using system dynamics: a case study of Dez Reservoir, Iran. Lake and Reservoir Management, 29(2): 126-140. frequency analysis of multivariate hydrological data. Water Resources Research, 43(9). Research, 68(3): 813-814. 
Joe, H. 1997. Multivariate models and multivariate dependence concepts: CRC Press.

443 Klein, B., Pahlow, M., Hundecha, Y., \& Schumann, A. 2010. Probability analysis of hydrological

Li, T., Wang, S., Fu, B., \& Feng, X. 2020. Frequency analyses of peak discharge and suspended sediment concentration in the United States. Journal of Soils and Sediments, 20(2): 11571168.

Nashwan, M. S., Ismail, T., \& Ahmed, K. 2018. Flood susceptibility assessment in Kelantan river basin using copula. Int. J. Eng. Technol, 7(2): 584-590.

Nelsen, R. B. 2006. An Introduction to Copulas. Springer, New York. MR2197664.

Sackl, B., \& Bergmann, H. 1987. A bivariate flood model and its application, Hydrologic Frequency Modeling: 571-582: Springer.

Salvadori, G., \& De Michele, C. 2007. On the use of copulas in hydrology: theory and practice. Journal of Hydrologic Engineering, 12(4): 369-380.

Salvadori, G., \& De Michele, C. 2010. Multivariate multiparameter extreme value models and return periods: A copula approach. Water Resources Research, 46(10).

She, D., \& Xia, J. 2018. Copulas-based drought characteristics analysis and risk assessment across the loess plateau of China. Water Resources Management, 32(2): 547-564.

Shiau, J.-T., Wang, H.-Y., \& Tsai, C.-T. 2010. Copula-based depth-duration-frequency analysis of typhoons in Taiwan. Hydrology Research, 41(5): 414-423.

Silverman, B. W. 1986. Density estimation for statistics and data analysis: CRC press.

sklar. 1959. Fonctions de repartition an dimensions et leurs marges. . Publ. Inst. Stat. Univ. Paris, 229-231. 
465 Volpi, E., \& Fiori, A. 2012. Design event selection in bivariate hydrological frequency analysis. $466 \quad$ Hydrological Sciences Journal, 57(8): 1506-1515.

467 Yue, S. 2000. The bivariate lognormal distribution to model a multivariate flood episode. $468 \quad$ Hydrological Processes, 14(14): 2575-2588.

469 Yue, S., Ouarda, T., Bobée, B., Legendre, P., \& Bruneau, P. 1999. The Gumbel mixed model for 470 flood frequency analysis. Journal of Hydrology, 226(1-2): 88-100.

471 Zhang, L., \& Singh, V. 2006. Bivariate flood frequency analysis using the copula method. Journal 472 of Hydrologic Engineering, 11(2): 150-164.

473 Zhang, L., \& Singh, V. P. 2007. Trivariate flood frequency analysis using the Gumbel-Hougaard 474 copula. Journal of Hydrologic Engineering, 12(4): 431-439. 
Figures

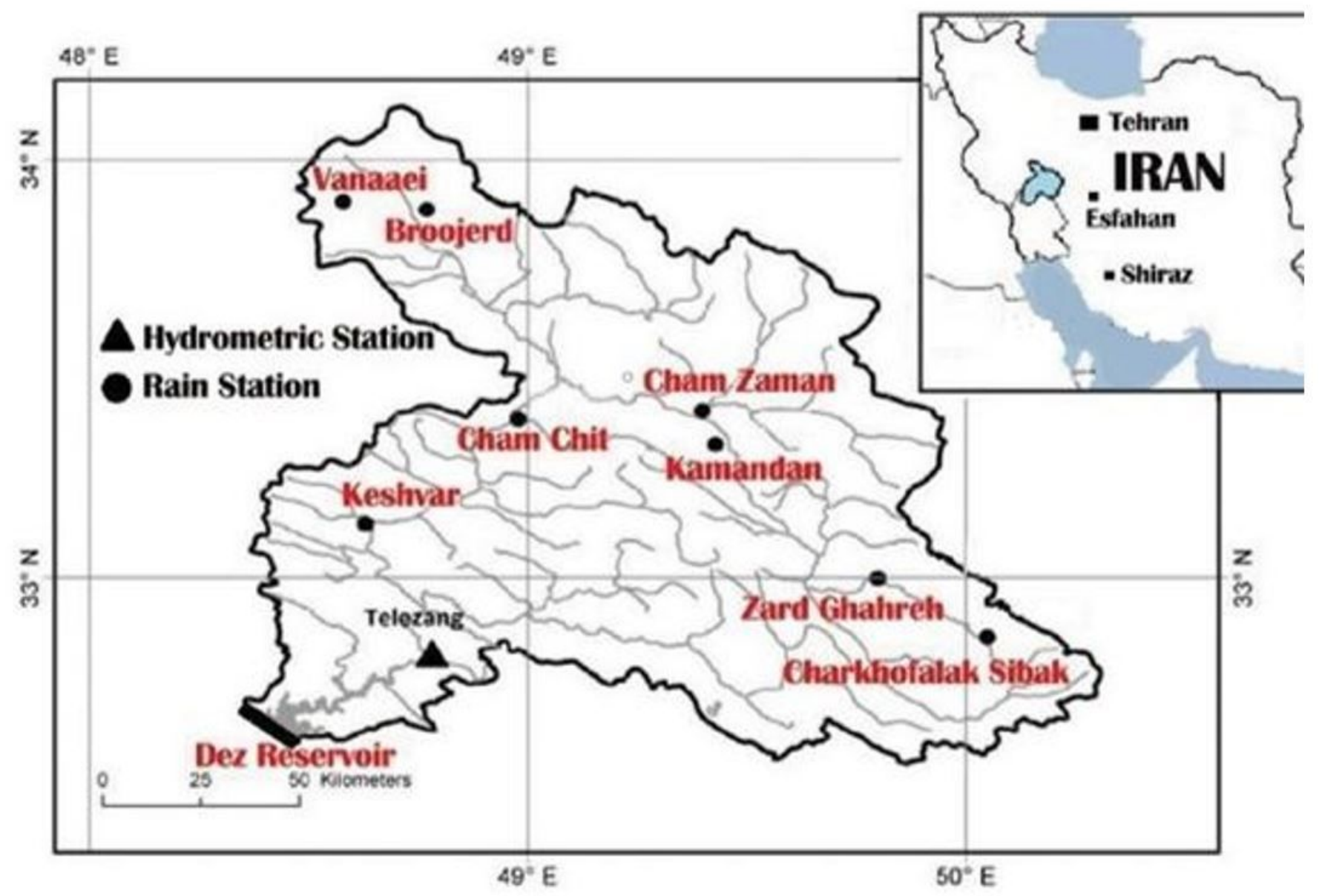

Figure 1

Location of Dez dam catchment and study area 


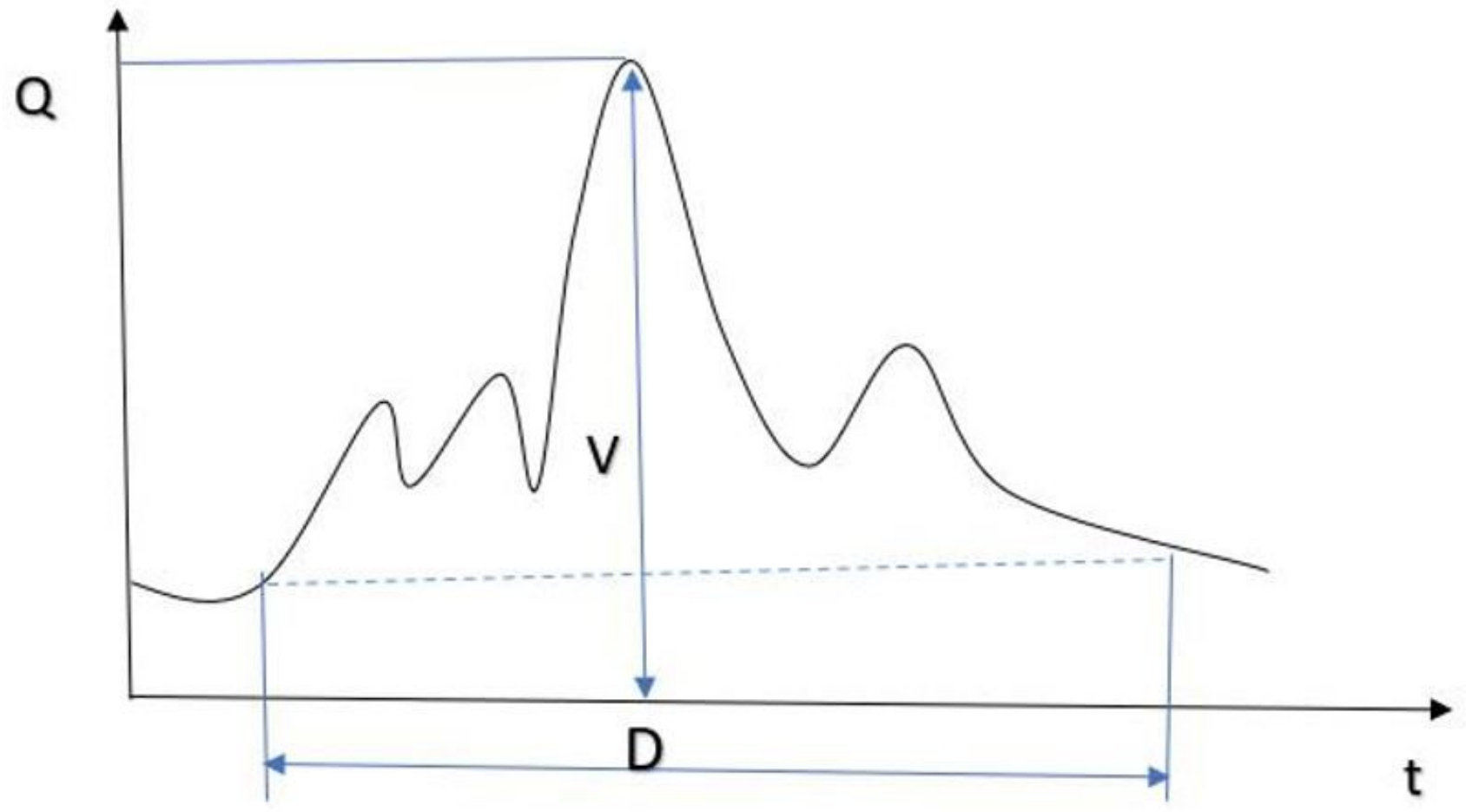

Figure 2

Determining flood characteristics 


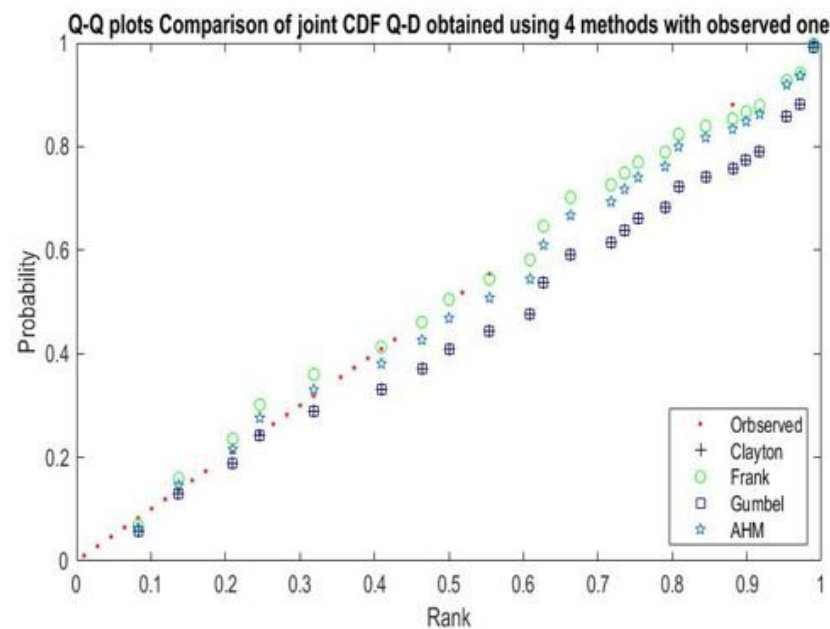

(a)

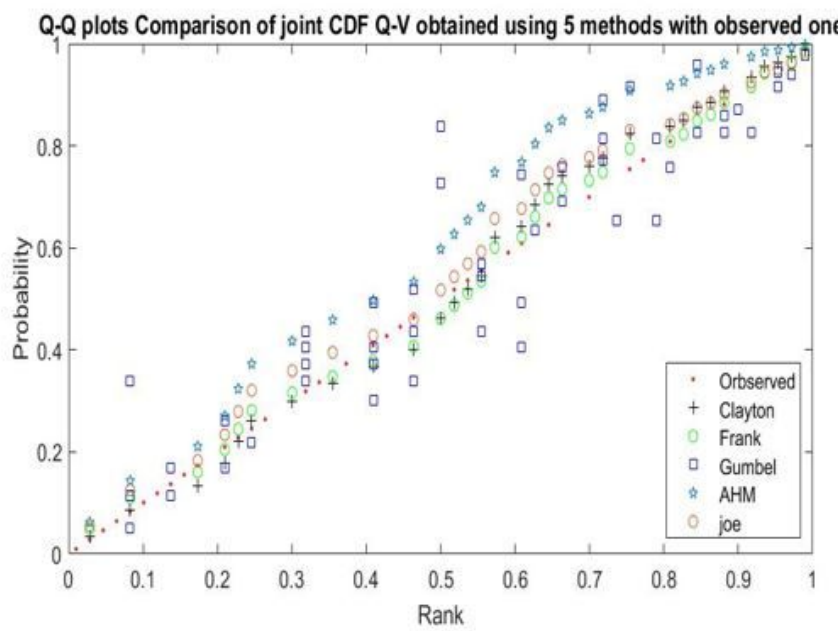

(b)

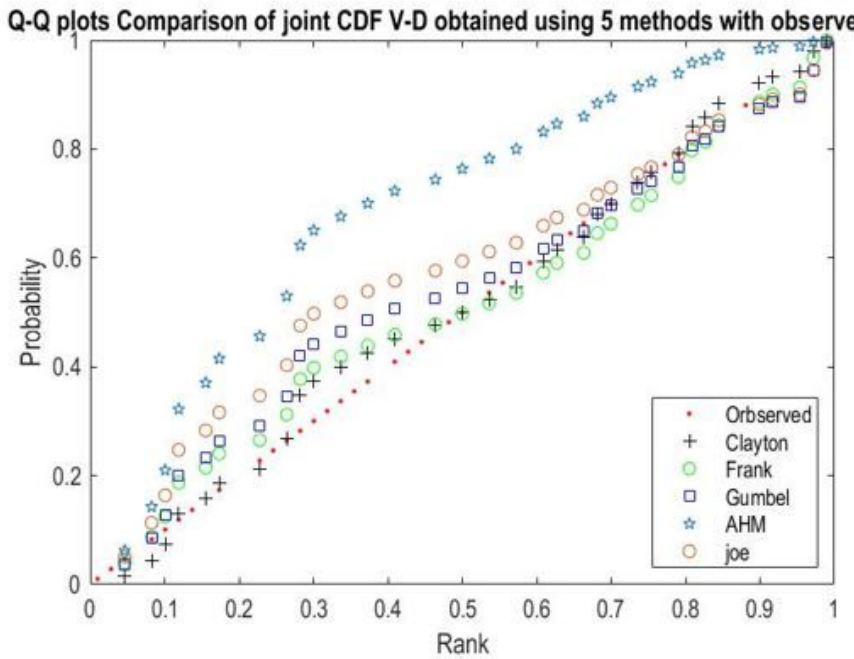

(c)

\section{Figure 3}

Curve Q-Q plot. (a) between flood peak and flood volume. (b) between flood peak and flood duration. (c) between the volume and duration of the flood 


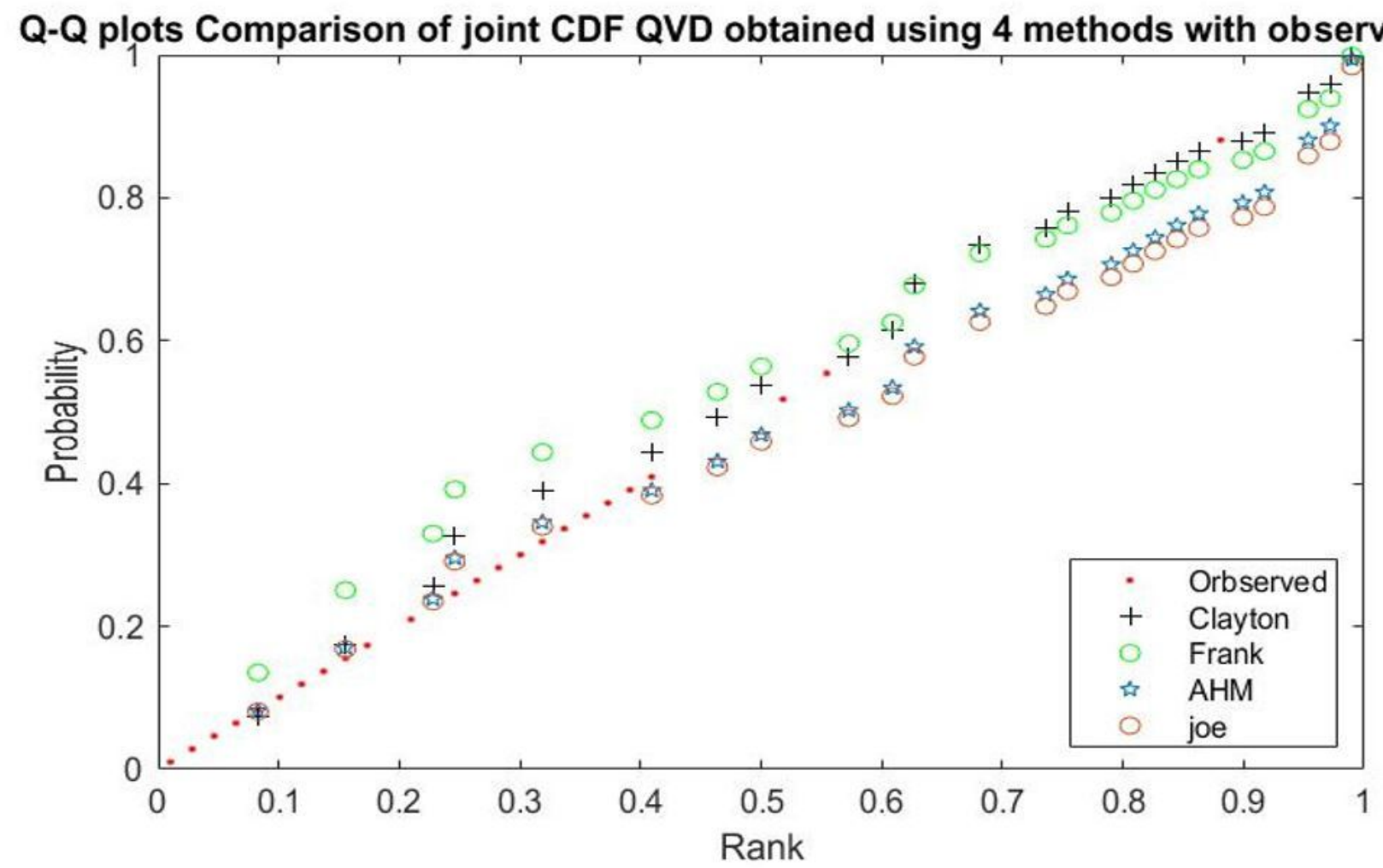

\section{Figure 4}

Curve Q_Q plot for three variables
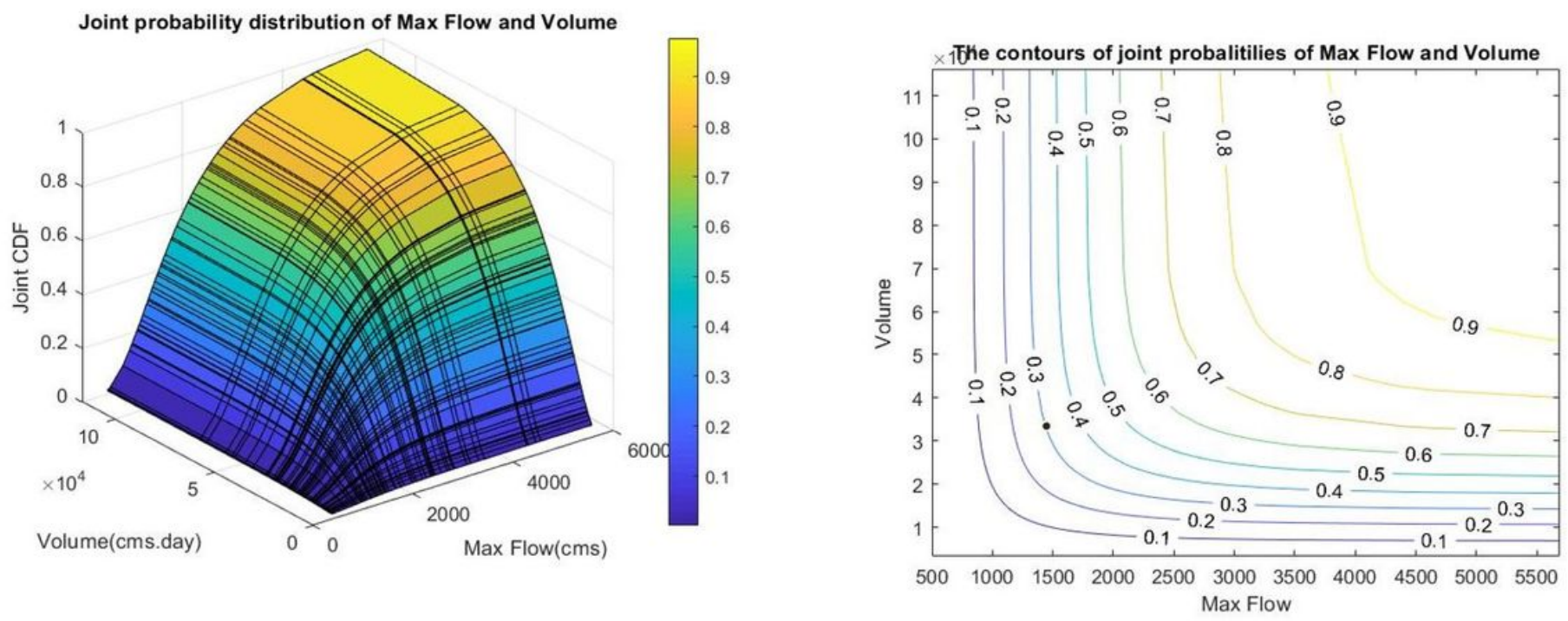

Figure 5

Joint Probability and contour lines of Frank distribution between flood peak and flood volume 

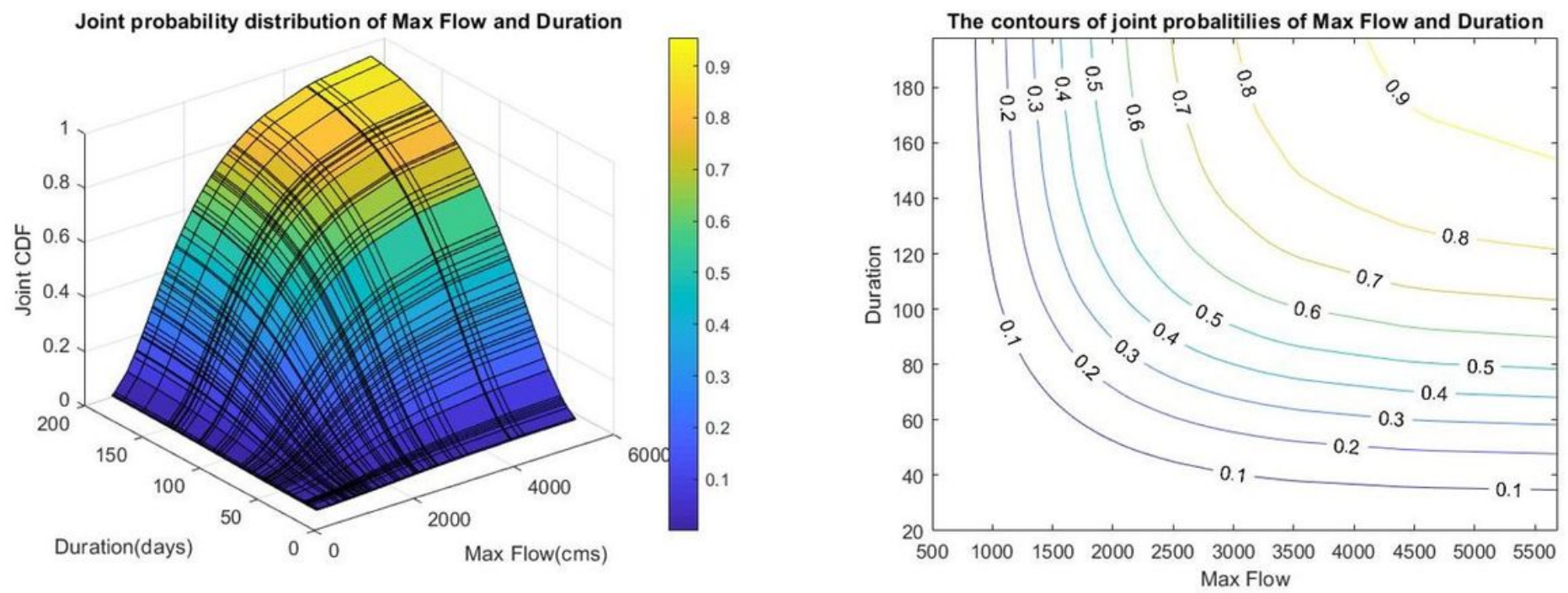

Figure 6

Joint Probability and contour lines of Frank distribution between flood peak and flood duration
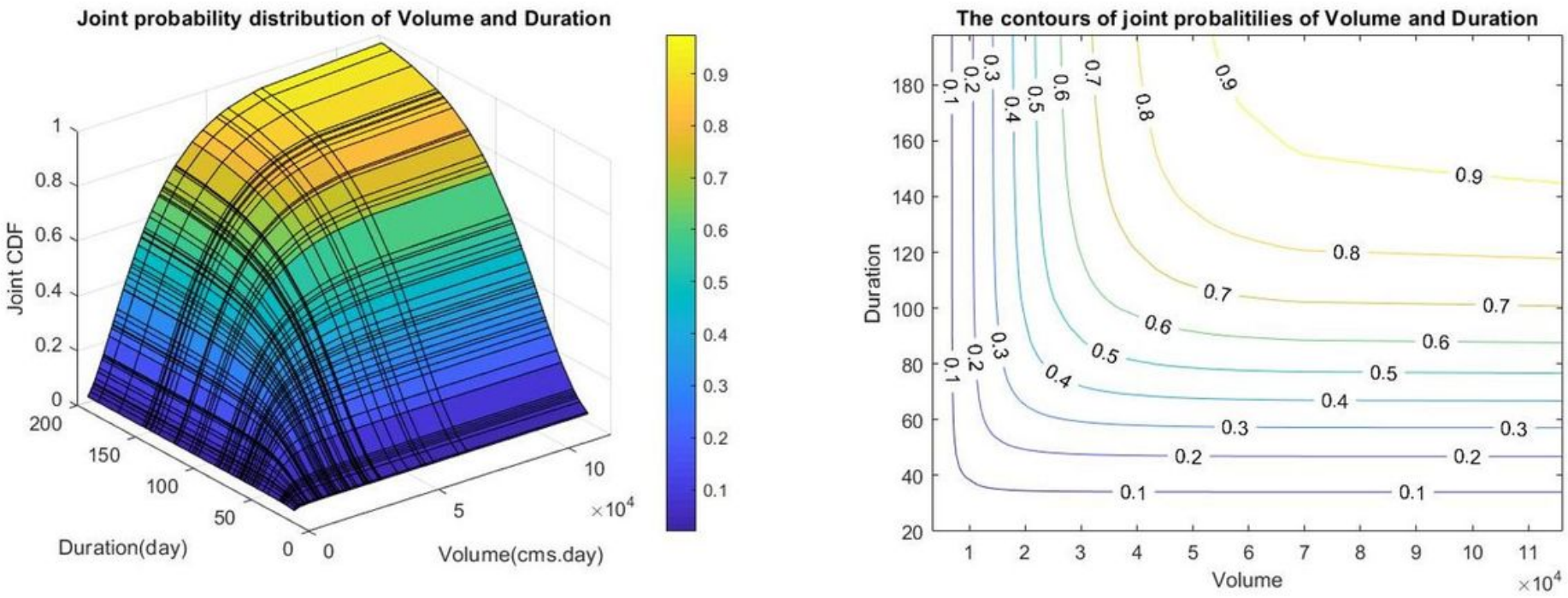

Figure 7

Joint Probability and contour lines of Clayton distribution between flood volume and flood duration 

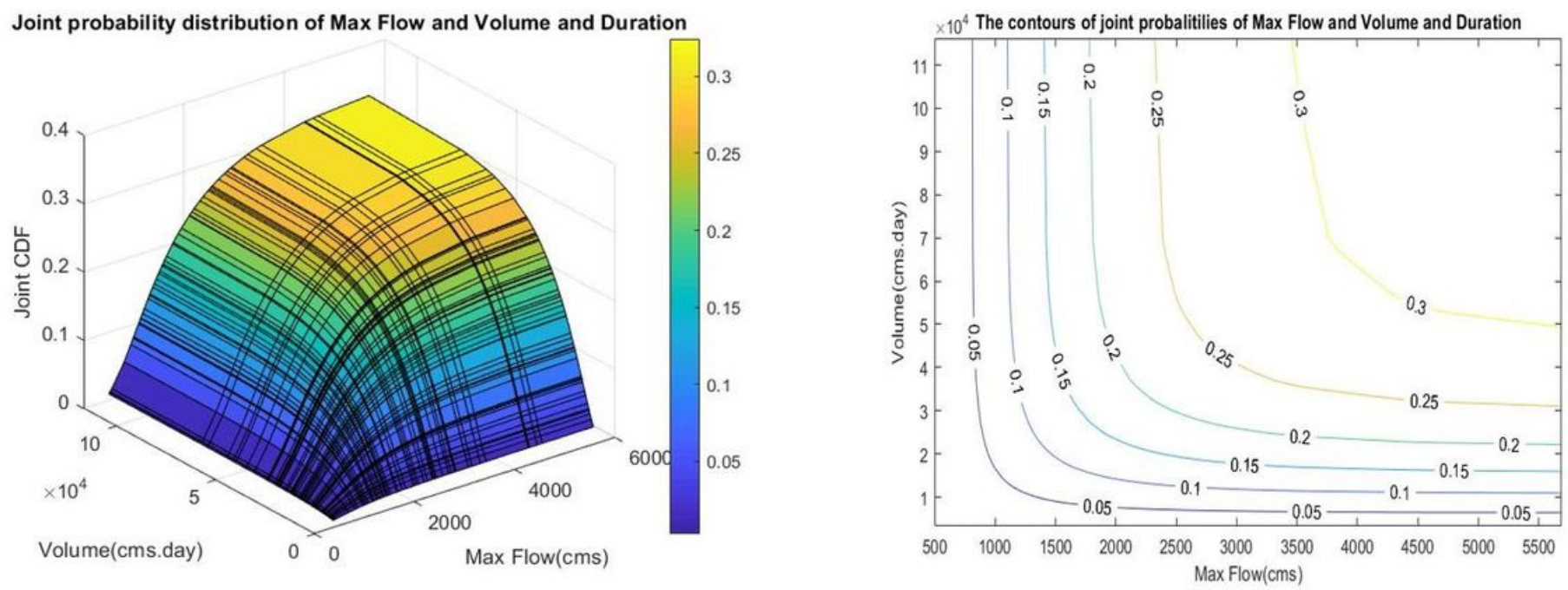

\section{Figure 8}

Joint Probability and contour lines of Clayton distribution between flood peak, volume, and duration
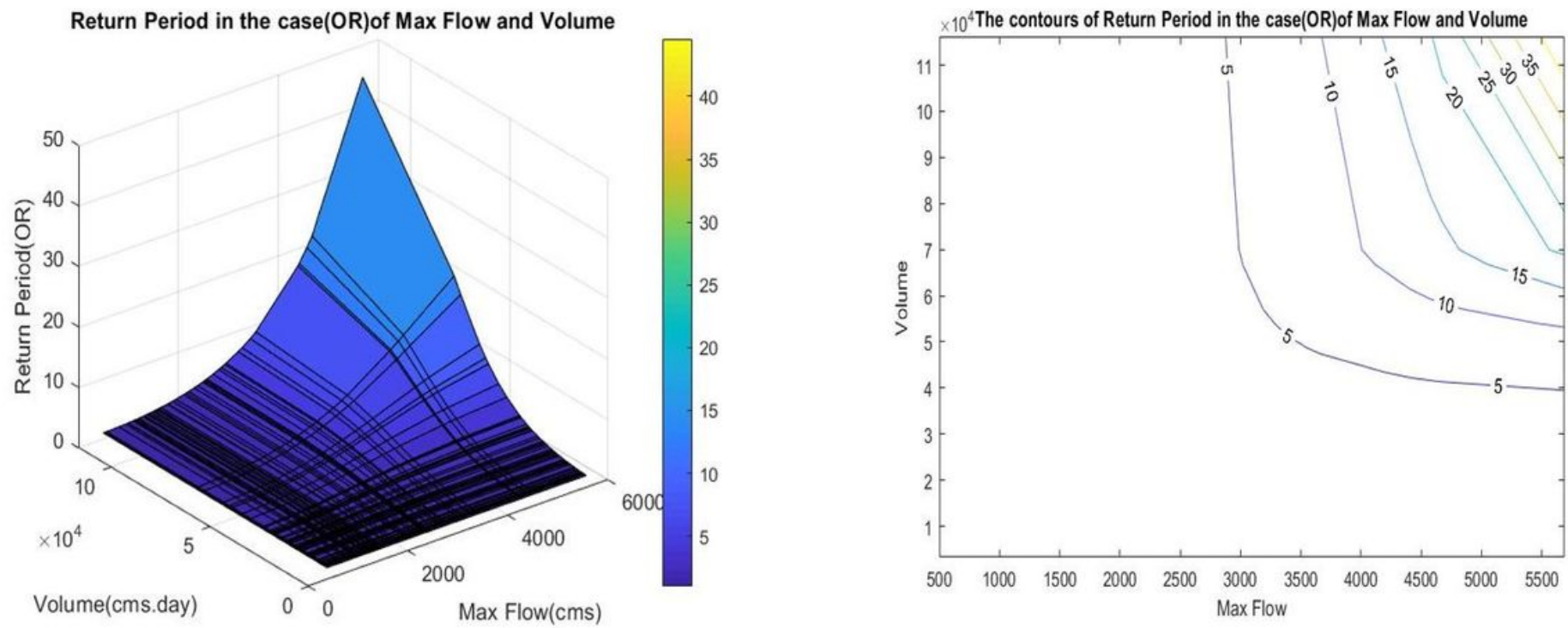

\section{Figure 9}

Return period and contour lines of the return period obtained by bivariate Frank function of type "or" between peak flow and flood volume 

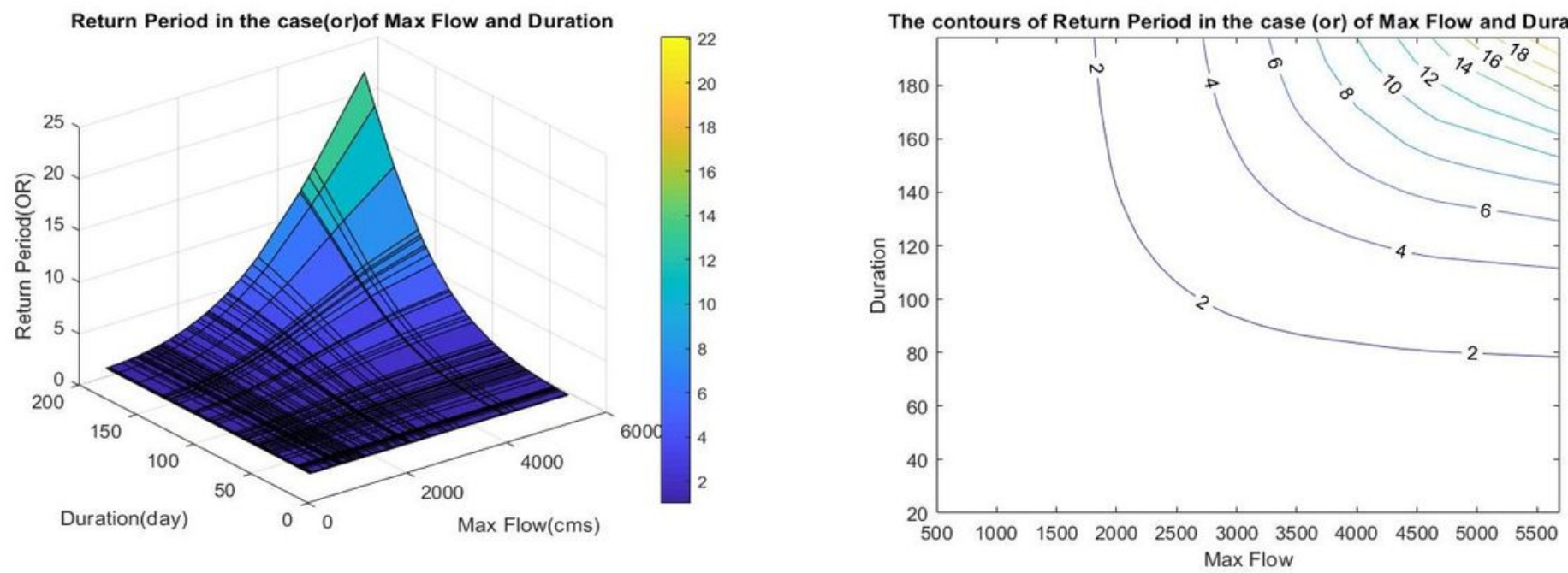

Figure 10

Return period and contour lines of the return period obtained by bivariate Frank function of type "or" between peak flow and duration
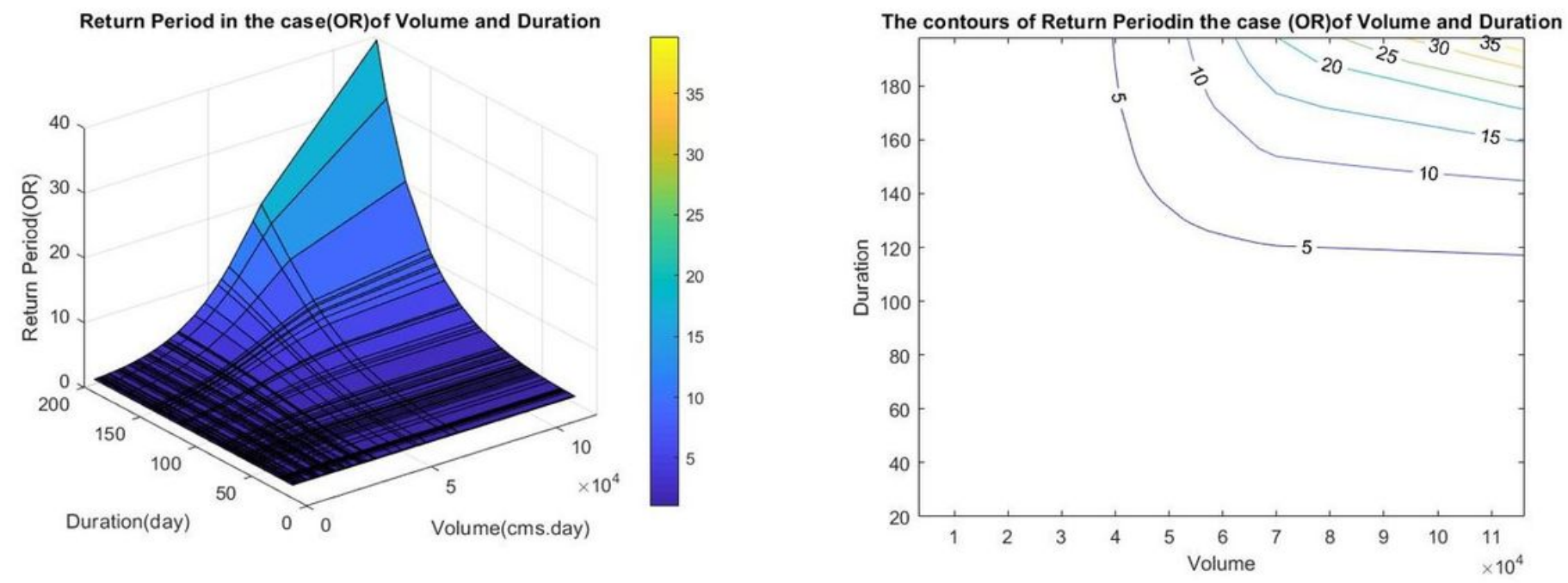

Figure 11

Return period and contour lines of the return period obtained by bivariate Clayton function of type "or" between volume and duration 

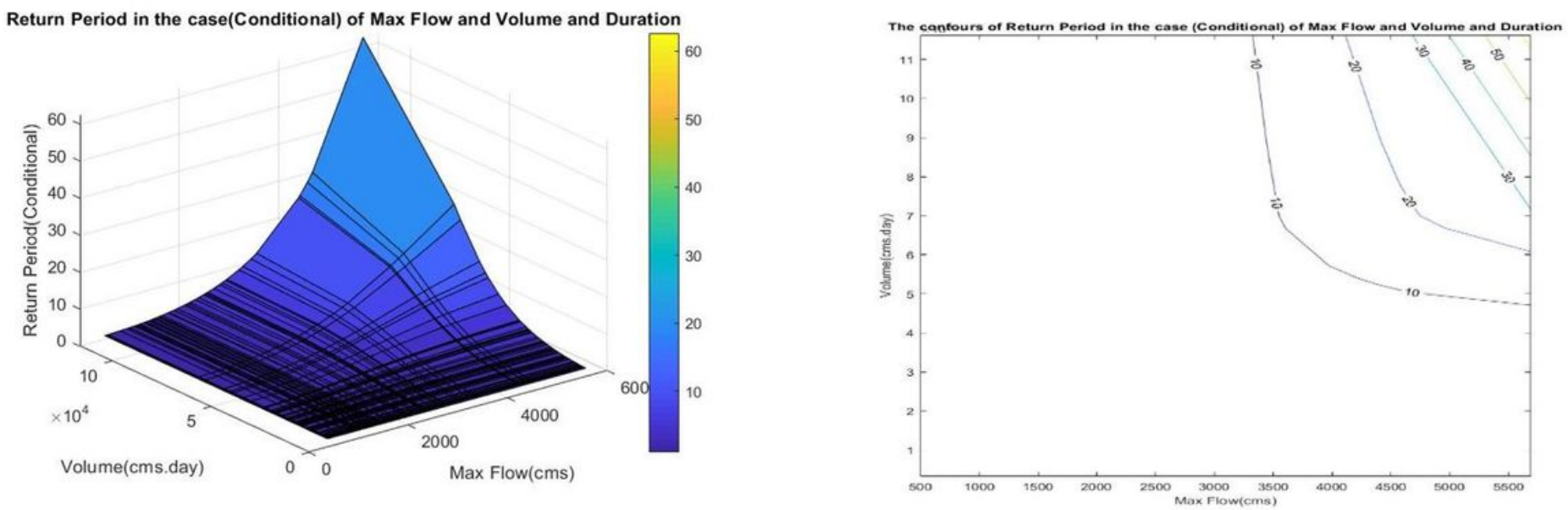

Figure 12

Conditional return period of three variables and contour lines for the 60-day flood duration 